Prepared for the U. S. Department of Energy

under Contract DE-AC05-76RL01830

\title{
Incorporation of NREL Solar Advisor Model Photovoltaic Capabilities with GridLAB-D
}

FK Tuffner

JL Hammerstrom

R Singh

October 2012

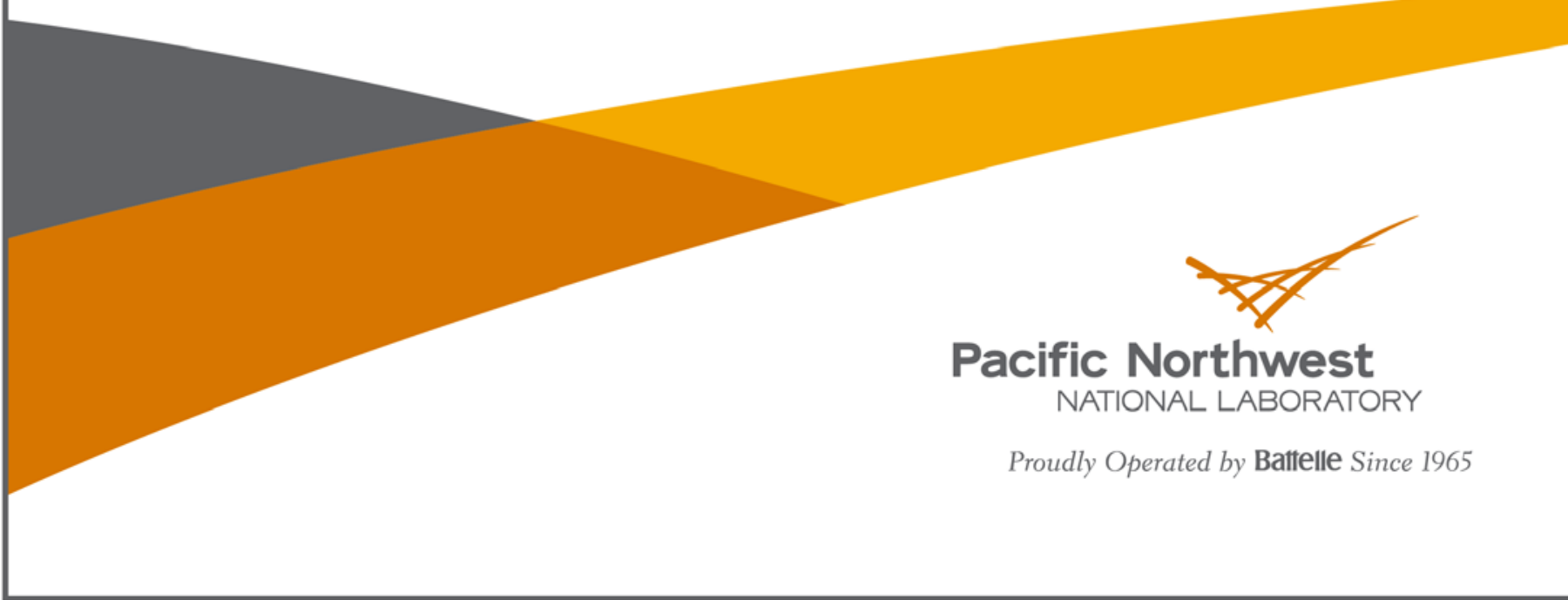




\title{
DISCLAIMER
}

This report was prepared as an account of work sponsored by an agency of the United States Government. Neither the United States Government nor any agency thereof, nor Battelle Memorial Institute, nor any of their employees, makes any warranty, express or implied, or assumes any legal liability or responsibility for the accuracy, completeness, or usefulness of any information, apparatus, product, or process disclosed, or represents that its use would not infringe privately owned rights. Reference herein to any specific commercial product, process, or service by trade name, trademark, manufacturer, or otherwise does not necessarily constitute or imply its endorsement, recommendation, or favoring by the United States Government or any agency thereof, or Battelle Memorial Institute. The views and opinions of authors expressed herein do not necessarily state or reflect those of the United States Government or any agency thereof.

\author{
PACIFIC NORTHWEST NATIONAL LABORATORY \\ operated by \\ BATTELLE \\ for the \\ UNITED STATES DEPARTMENT OF ENERGY \\ under Contract DE-AC05-76RL01830
}

Printed in the United States of America

Available to DOE and DOE contractors from the Office of Scientific and Technical Information,

P.O. Box 62, Oak Ridge, TN 37831-0062; ph: (865) 576-8401 fax: (865) 576-5728 email:

reports@adonis.osti.gov

\begin{abstract}
Available to the public from the National Technical Information Service, U.S. Department of Commerce, 5285 Port Royal Rd., Springfield, VA 22161 ph: (800) 553-6847 fax: (703) 605-6900

email: orders@ntis.fedworld.gov online ordering: http://www.ntis.gov/ordering.htm
\end{abstract}

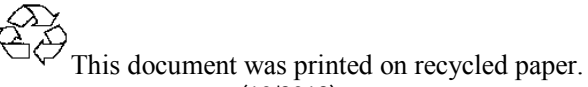




\section{Incorporation of NREL Solar Advisor Model Photovoltaic Capabilities with GridLAB-D}

FK Tuffner

JL Hammerstrom

R Singh

October 2012

Prepared for

the U. S. Department of Energy

under Contract DE-AC05-76RL01830

Pacific Northwest National Laboratory

Richland, Washington 99352 


\section{Summary}

This report provides a summary of the work updating the photovoltaic model inside GridLAB-D. The National Renewable Energy Laboratory Solar Advisor Model (SAM) was utilized as a basis for algorithms and validation of the new implementation. Subsequent testing revealed that the two implementations are nearly identical in both solar impacts and power output levels. This synergized model aides the system-level impact studies of GridLAB-D, but also allows more specific details of a particular site to be explored via the SAM software. 


\section{Acknowledgement}

The authors wish to thank the Department of Energy, Office of Electricity Delivery and Energy Reliability for funding this work and GridLAB-D through the years. Special thanks are also needed for Mr. Peter Gotseff and Dr. Joshua Hambrick at the National Renewable Energy Laboratory for their assistance testing and understanding the photovoltaic model. 


\section{Contents}

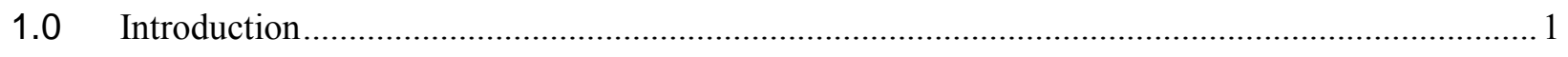

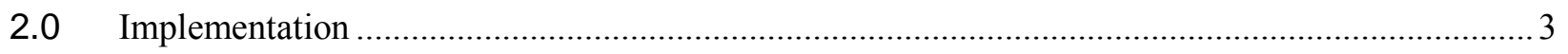

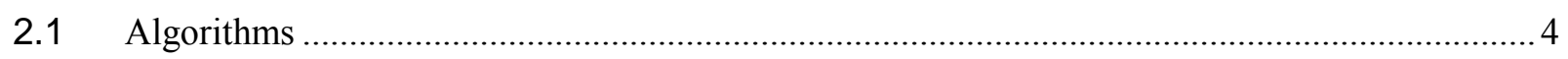

2.1.1 SOLPOS - Solar Position Model ................................................................................ 5

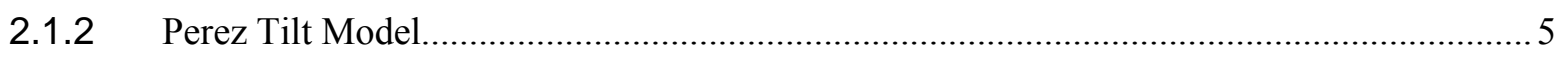

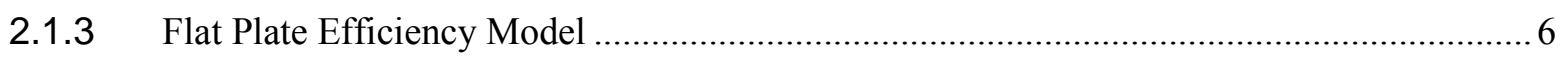

2.2 Validation - NREL Solar Advisor Model...................................................................... 6

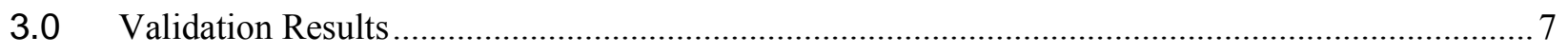

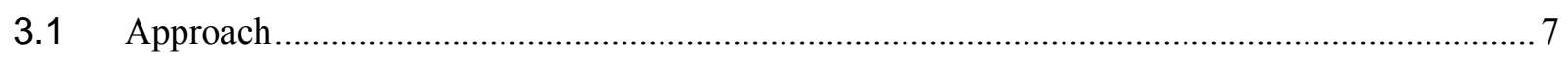

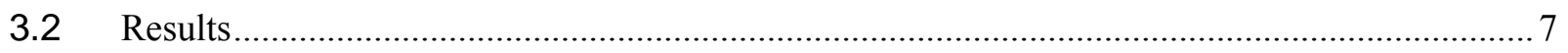

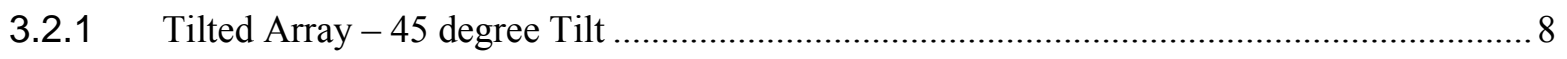

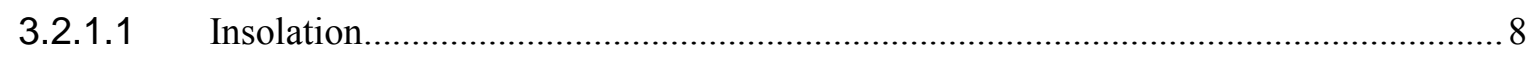

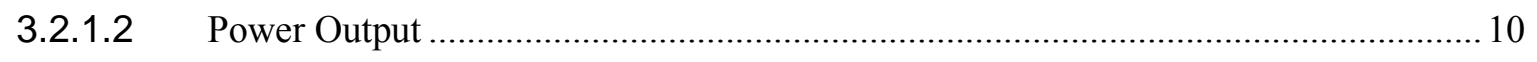

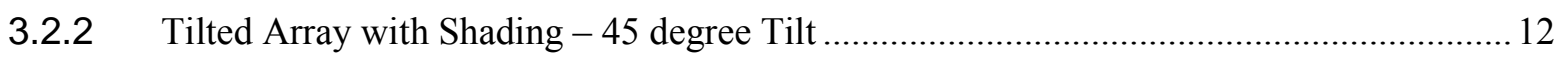

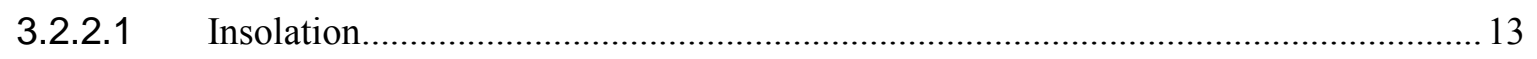

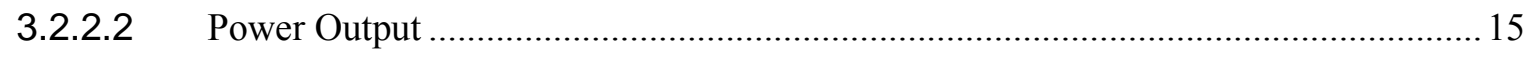

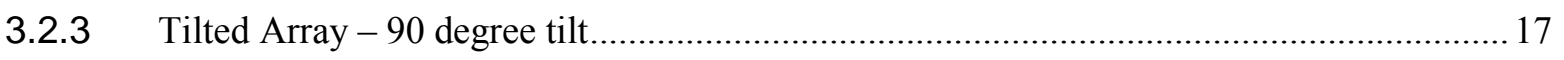

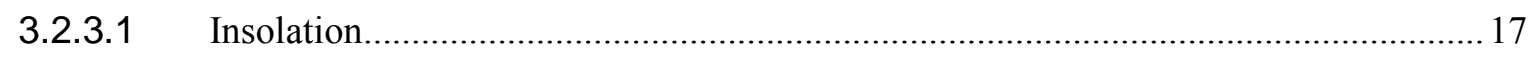

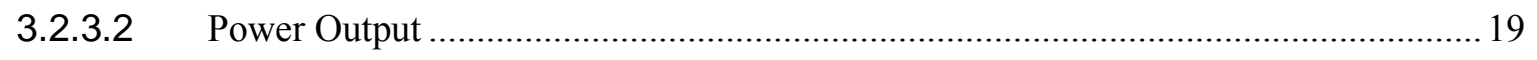

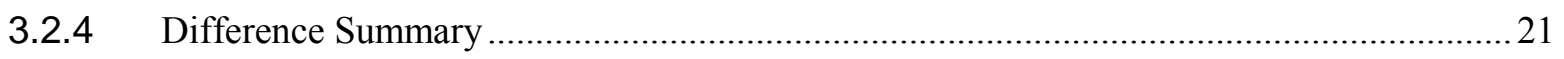

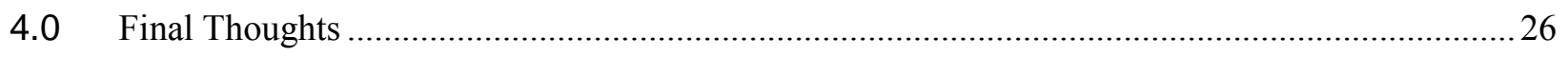

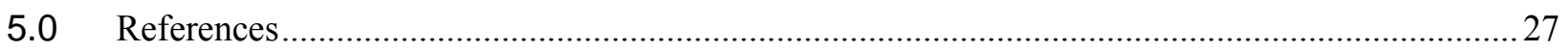




\section{Figures}

Figure 1. Comparison of calculated solar insolation for GridLAB-D solar models ................................. 3

Figure 2. Comparison of power output for new and old GridLAB-D solar and efficiency models............. 4

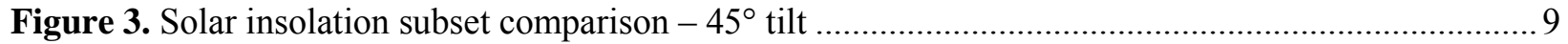

Figure 4. Insolation differences between GridLAB-D and SAM for entire year - 45 $5^{\circ}$ tilt ..................... 10

Figure 5. PV array power output comparison for data subset $-45^{\circ}$ tilt .............................................. 11

Figure 6. Power output differences between GridLAB-D and SAM for entire year $-45^{\circ}$ tilt ................. 12

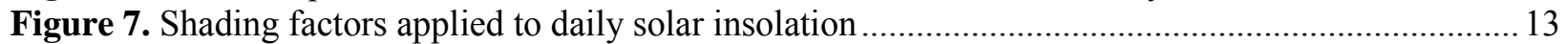

Figure 8. Solar insolation subset comparison $-45^{\circ}$ tilt with shading factors ........................................ 14

Figure 9. Insolation differences between GridLAB-D and SAM for entire year $-45^{\circ}$ tilt with shading

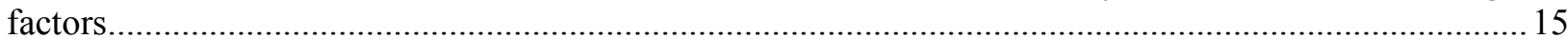

Figure 10. PV array power output comparison for data subset $-45^{\circ}$ tilt with shading factors................ 16

Figure 11. Power output differences between GridLAB-D and SAM for entire year $-45^{\circ}$ tilt with shading

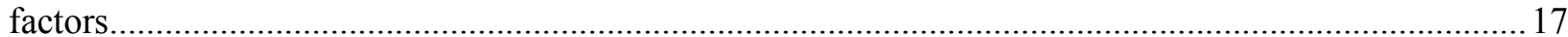

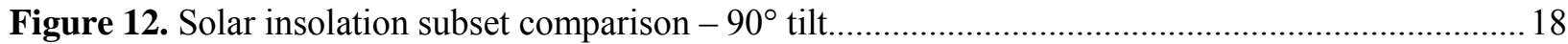

Figure 13. Insolation differences between GridLAB-D and SAM for entire year $-90^{\circ}$ tilt.................... 19

Figure 14. $\mathrm{PV}$ array power output comparison for data subset $-90^{\circ}$ tilt .............................................20

Figure 15. Power output differences between GridLAB-D and SAM for entire year $-90^{\circ}$ tilt ...............2 21

Figure 16. Differences for direct-normal irradiance between GridLAB-D and SAM for entire year $-45^{\circ}$

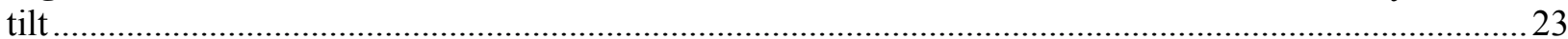

Figure 17. Differences for diffuse-horizontal irradiance between GridLAB-D and SAM for entire year $45^{\circ}$ tilt

Figure 18. Signed differences for diffuse-horizontal irradiance between GridLAB-D and SAM for entire year $-45^{\circ}$ tilt.

\section{Tables}

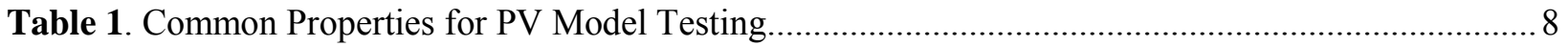

Table 2. Magnitude of Difference for Different Scenarios ................................................................ 22 


\subsection{Introduction}

The deployment of new grid technologies and policies has diversified the characteristics and capabilities of distribution-level end points on the system. Some of these capabilities, such as net-metering practices, coupled with societal goals of sustainable energy practices and various incentives, have made the deployment of distributed generation very popular. In 2010, $84 \%$ of the shipped photovoltaic (PV) modules were shipped toward distributed-generation purposes [1]. Building owners of residential, commercial, and even industrial fields can purchase and deploy rooftop or other fixed-mounting PV arrays very easily. As more of these deployments come online, their impacts to the distribution power system are of greater concern and need to be evaluated. To properly evaluate the impacts of these new deployments, it is necessary to conduct detailed simulations and analysis.

The modeling of distributed generation has been approached from two different perspectives. The deployed devices have impacts for both the end-use customer and the larger power system. At the customer level, the analysis typically requires detailed models of energy production, costs models associated with the deployment and operation of the device, and how these two models interact. The National Renewable Energy Laboratory (NREL) Solar Advisor Model (SAM) software provides this level of functionality [2]. The software allows renewable generation technologies to be simulated at a device level and allows the customer to explore payback periods, annual energy output, and annual financial impacts of such devices.

At the larger power system level, the impacts on the electrical characteristics and equipment ratings are often of interest. This includes impacts between the distribution powerflow as a whole and the end-use behavior of the specific customer or PV-connected point. To model these interactions, the GridLAB-D software package was utilized. GridLAB-D is a Department of Energy, Office of Electricity Delivery and Energy Reliability-funded software package developed at the Pacific Northwest National Laboratory [3]. GridLAB-D provides a suite of capabilities for modeling distribution systems from the sub-transmission system down to the final appliance in a customer's home or business. With proper models and system information, GridLAB-D can be successfully used to evaluate existing conditions and new technology impacts on a distribution system.

The underlying solar mechanics of the photovoltaic model within GridLAB-D were written primarily for impacting the thermal model of buildings. The model was designed to model the contributions solar heating will bring to an equivalent thermal model of a building. The particular model implemented was based off the algorithms in [4]. Many of the building solar processes are governed by longer time constants, so the model was of sufficient detail to meet these needs. However, for electrical effects of modern photovoltaic systems, the model was not as accurate as more contemporary implementations.

The primary task of this project was to bring the GridLAB-D solar model in line with more modern implementations. This improvement was primarily aimed at improving the accuracy and effectiveness of the photovoltaic array model. With faster updating and more modern model practices, the output of a single photovoltaic array and an aggregate population of many arrays would be properly represented on the distribution system. In a simple example later in the paper, the difference in electricity generation between the old and new model on a $4 \mathrm{kVA}$ array was approximately $640 \mathrm{kWh}$ for one year of simulation. This difference represents almost $12.6 \%$ of the expected, validation energy output. 
NREL has produced the SAM software to help evaluate economic impacts and viability of renewable generation sources [2]. As part of this evaluation, the SAM software incorporates more accurate solar position and photovoltaic models to provide an accurate representation of the system. The GridLAB-D model alignment utilized the same base models incorporated into the SAM software. Even with the same base models, subtle differences in implementation will still exist. These differences will be highlighted in later sections. Even with the slight nuances, the common base algorithms allow SAM to provide a validation base for the newly implemented GridLAB-D models. 


\subsection{Implementation}

Ensuring the output of a photovoltaic array in GridLAB-D is accurate for distribution studies required updating the underlying model. The existing model served well for solar thermal impacts on buildings, but was not sufficient for modern PV arrays and their impacts on the local power system. To provide this capability, a newer solar irradiance and position algorithm, was necessary. NREL's Solar Advisor Model is well established and leverages off of NREL's established expertise in that field.

Figure 1 shows a comparison for the solar insolation on the plane of the PV array for the legacy GridLAB-D model compared to the new SAM-based GridLAB-D model. Figure 2 shows the corresponding power output for different combinations of the position model and panel efficiency model. It is clear from Figure 1 that some significant differences existed even on the raw solar insolation. Many of the values were 30 minutes or more shifted and diffuse horizontal radiation components were not properly represented. On average, the legacy model had an incident radiation value that was $15 \%$ to $20 \%$ lower than the new SAM-based solar model. After translating this insolation into a power value for Figure 2, the vast differences in output power between the old and new implementation are also visible. Clearly this large of a difference could have significant impacts on distribution feeder analysis.

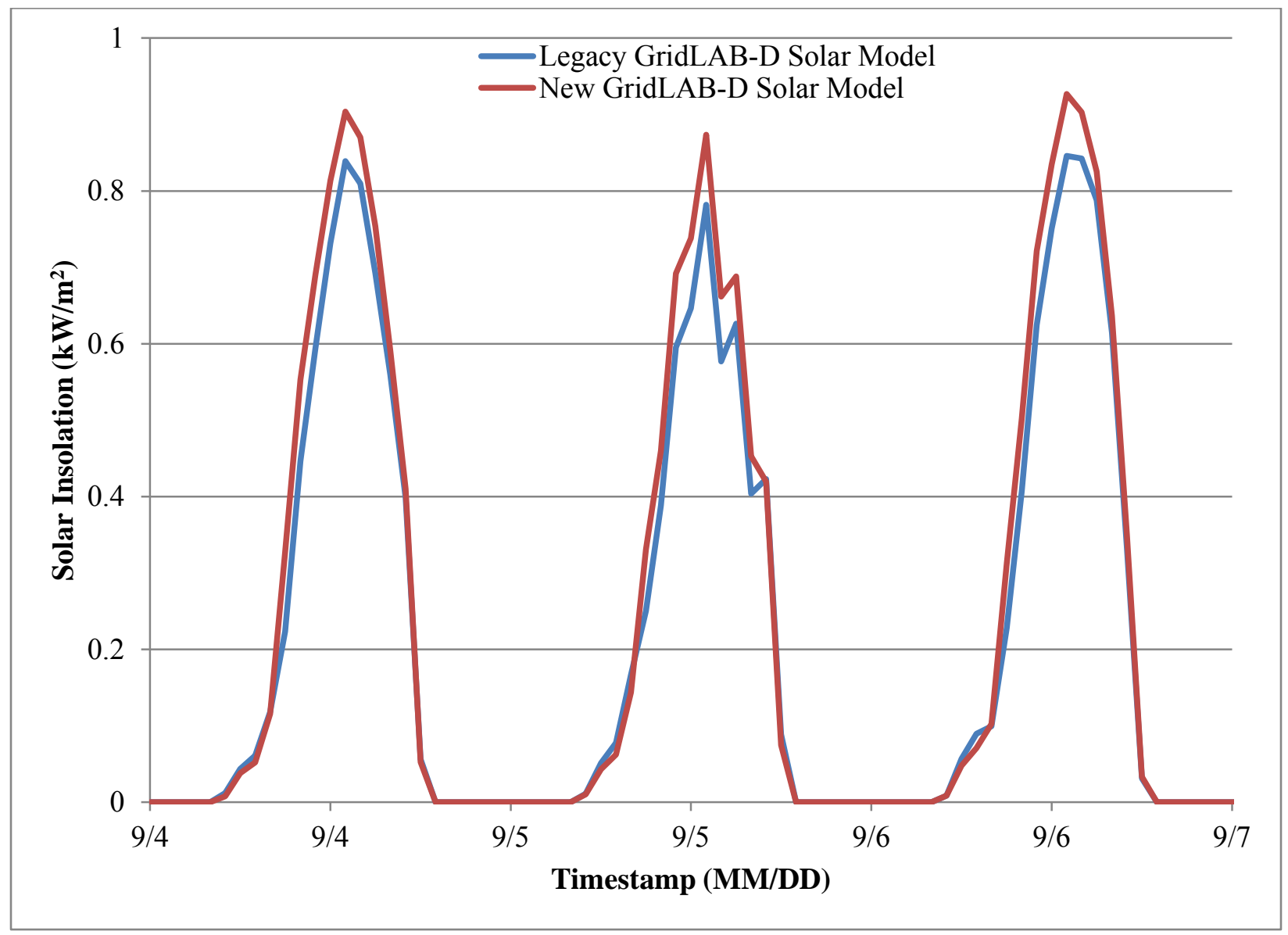

Figure 1. Comparison of calculated solar insolation for GridLAB-D solar models 


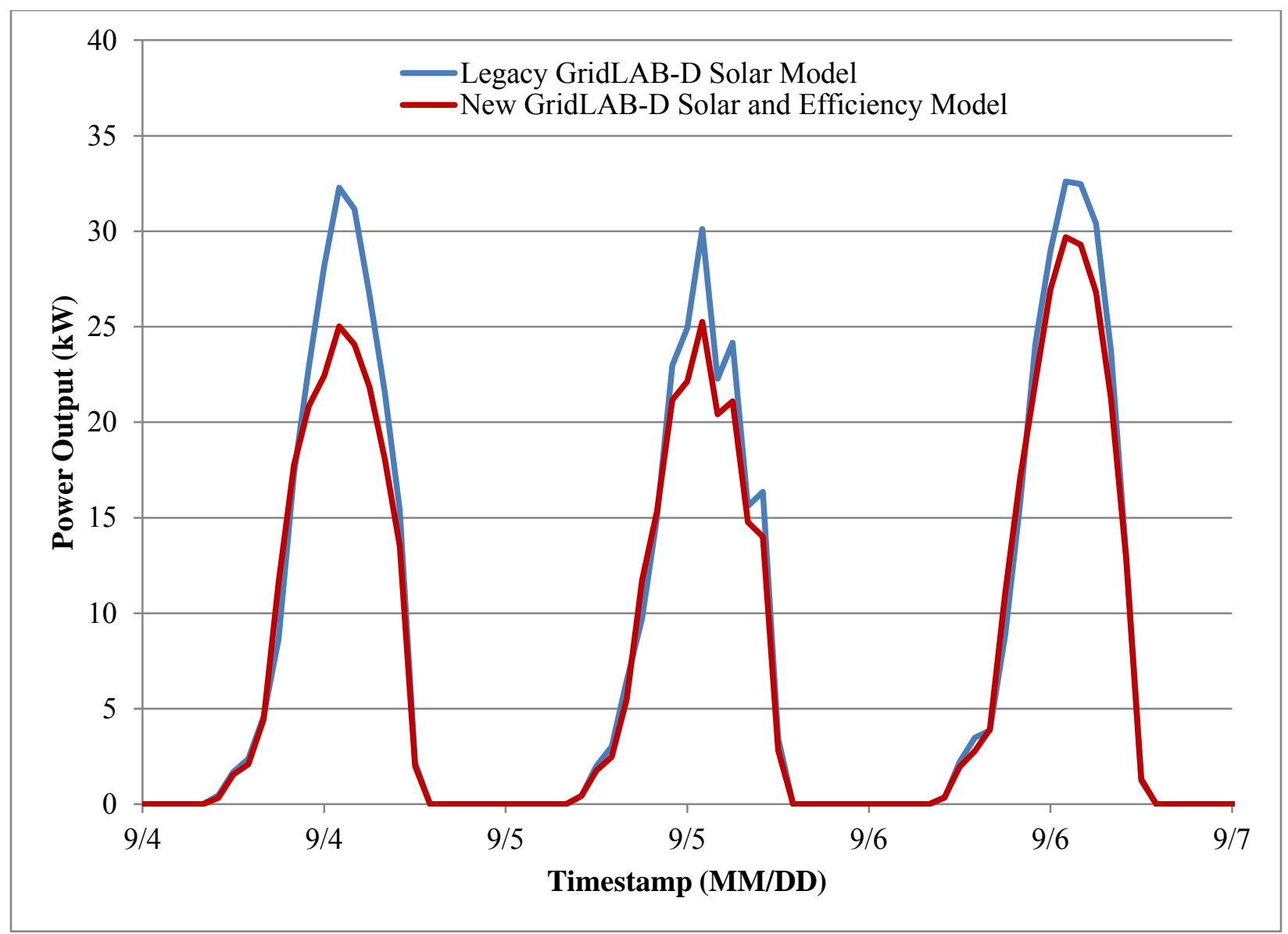

Figure 2. Comparison of power output for new and old GridLAB-D solar and efficiency models

\subsection{Algorithms}

The NREL-SAM software package includes numerous features and capabilities relating to renewable energy generation. For the purposes of the GridLAB-D photovoltaic array, only the electrical generation impacts of photovoltaic generation were desired. Even under this limited subset, SAM provides significantly more functionality for a single array than GridLAB-D. However, SAM is oriented more at individual-level deployments, while GridLAB-D is typically used for system-level studies. This distinction is a significant influence in how much functionality each model requires.

For system-level studies, the impact on the distribution feeder and electrical system are of concern. For a photovoltaic system, the electrical characteristics of voltage impacts and power generated are the largest influences of the powerflow. Having an accurate solar, and in turn, power conversion model is necessary to represent these effects. Conversely, SAM is more for individual-level deployments. While the basic solar model is essentially the same, further functionality relating to the economics and initial costs of the PV array are included. This level of detail could be incorporated into GridLAB-D, but it represents a granularity not needed on larger, system-level impacts. However, building off of a common, base algorithm between the two software packages will allow transitions between these levels of detail as the end user sees fit. 
One primary capability and three models utilized inside the SAM software were replicated inside GridLAB-D. Prior to this work, GridLAB-D only utilized a flat-plate array parallel with the earth's surface. The primary capability implemented was for fixed arrays at various tilt angles. With this capability, incident solar radiation into the model needed to be modeled properly. The first two algorithmic changes affect how incident solar radiation is computed for the photovoltaic array. While the existing algorithm incorporated aspects of both direct normal and diffuse horizontal radiation, the specific amount of both types impacting the array required some refinement. The third model incorporated thermal heating impacts on solar output. All three algorithms are briefly discussed in the following subsections.

\subsubsection{SOLPOS - Solar Position Model}

To properly calculate the values of the direct normal sunlight (direct line of sight to the sun), the Solar Position and Intensity 2.0 algorithm was utilized [5]. This algorithm provided more correction for astronomical variations in the earth's path through space, as well as environmental effects on the direct sunlight. The specifics of the SOLPOS model are very complex and actually represent a set of equations from many individual sources that factor in a variety of influences. As such, specific details are available in [5] and the source code of [3]. The final results of the algorithms are a more representative value of direct solar radiation reaching the plane of the photovoltaic array at different times of the day. With this change in place, the difference from the SAM validation model and the new GridLAB-D model reduced by a factor of 1.4. Even with this change, a significant amount of difference still exists between the two models.

\subsubsection{Perez Tilt Model}

The second significant component of updated solar irradiation model was a better model of diffuse horizontal radiation. Diffuse horizontal radiation is not direct sunlight, but sunlight scattered through the clouds and atmosphere, as well as reflected off the ground nearby. On days with significant cloud transients or heavier cloud cover, diffuse radiation can become the only input towards the PV array's power generation capability. The well-established Perez tilt model was selected to properly factor diffuse radiation impacts into the photovoltaic array [6]. The Perez tilt model factors not only the tilt of the PV array into the calculation, but also atmospheric effects that influence the PV array output.

The Perez tilt model begins with a classification on the sky clearness. Coupled with a brightness index, a series of luminous efficacy and zenith luminance model coefficients are obtained. These coefficients are used to compute the diffuse horizontal scalar component using [6]:

$$
P_{\text {scale }}=\frac{\left(1-F_{1}\right)(1+\cos (\theta))}{2}+\frac{a \cdot F_{1}}{b}+F_{2} \sin (\theta)
$$

where $\theta$ is the tilt angle, $F_{1}$ and $F_{2}$ are the coefficients based on luminous efficacy and zenith luminance, and $a$ is the cosine of the incidence angle on the array. The value for $b$ is selected as either 0.087 or the cosine of the solar zenith angle, whichever is larger. The final $P_{\text {scale }}$ value is multiplied by the measured diffuse horizontal component (from a weather file) and applied to the full insolation accumulation.

Combined with the SOLPOS algorithm, the difference from the SAM-based insolation was reduced by a factor of greater than 27 from the original GridLAB-D implementation. 


\subsubsection{Flat Plate Efficiency Model}

After the incident solar radiation has been properly calculated, an updated efficiency model was also replicated from SAM. The default GridLAB-D model utilized a very simple temperature correction that did not fully account for solar heating of the array. The SAM software utilizes many efficiency models, with the flat plate simple efficiency model being the default [2]. Incorporating this temperaturedependent efficiency allowed more precise modeling of the output during midday peak solar output times.

The flat plate efficiency model begins with calculation of the back plate temperature and solar cell temperature, individually calculated as:

$$
\begin{gathered}
T_{\text {Back }}=E_{\text {Incident }} \cdot \exp \left(a+b \cdot v_{\text {wind }}\right)+T_{\text {Ambient }} \\
T_{\text {Cell }}=T_{\text {Back }}+\frac{E_{\text {Incident }}}{E_{0}} \cdot d T
\end{gathered}
$$

$E_{\text {Incident }}$ is the incident diffuse and direct normal solar radiation; $E_{0}$ is a reference value of $1000 \mathrm{~W} / \mathrm{m}^{2} ; a, b$, and $d T$ are constants for specific panel and mounting types; $T_{\text {Ambient }}$ is the ambient outside temperature; and $v_{\text {wind }}$ is the current wind speed. These values are used to calculate the final temperature correction of

$$
F_{\text {Temp Corr }}=1+\gamma \cdot\left(T_{\text {Cell }}-25.0^{\circ} \mathrm{F}\right) \text {, }
$$

where $\gamma$ is a maximum power temperature coefficient for the array. The temperature efficiency is applied to the final DC output power of the array. Implementing the flat plate efficiency model reduced the difference between the GridLAB-D and SAM simulations by a factor of 25 over the base efficiency value.

\subsection{Validation - NREL Solar Advisor Model}

Once the updated irradiance models and temperature efficiency values were implemented, the overall GridLAB-D PV array output needed to be validated against a known case. The base models were selected due to their availability and implementation in the NREL SAM software. Using identical parameters in both software packages, identical results in the solar irradiance and PV array output should be obtained. 


\subsection{Validation Results}

The implementation of the updated solar position and efficiency was a necessary step in creating an accurate representation of PV arrays in GridLAB-D. However, misinterpretations of the reference paper, differences in notation, and other unexpected items could cause an invalid result to come from the model. To validate the implemented code, NREL SAM was used as a comparison source for ensuring the updated PV results matched a known implementation.

\subsection{Approach}

While the theory of the software validation is sound, the actual implementation of the two algorithms is not identical in GridLAB-D and SAM. Differences in how the individual values are encoded, the specific compiler utilized, and overall processing order will influence the numbers very slightly, so an exact fit is not expected. However, these factors should produce only very small changes in the answers, on the order of one part in one-thousand, or less. Since some slight deviations are possible with these effects, validation was conducted on a year-long simulation to examine the total difference between the two software implementations. An entire year of solar irradiance and PV output data was obtained for both pieces of software. A final, overall percent difference value was obtained using the formula

$$
\%_{\text {Difference }}=\frac{\sum\left|V_{G L D}-V_{S A M}\right|}{\sum V_{S A M}} \cdot 100
$$

where $V_{G L D}$ is the value from GridLAB-D and $V_{S A M}$ is the value from SAM. It is important to note this is an accumulation of absolute difference, so deviations above and below the SAM value are treated equally and will not cancel each other out. Using the formula of (5), differences below $1 \%$ were acceptable for the GridLAB-D implementation over a full year.

The accumulated absolute error was selected as a means to determine overall differences in the plot, especially as they may influence a year-long simulation. Other error metrics, like root-mean-squarederror (RMSE), would provide a good, overall comparison of the two models. However, they would downplay the influence of the smaller, aggregate difference over a year. For system-level studies, this yearly accumulation of error can be especially important to understand, particularly when energy impacts

are being compared. Understanding how the basic model may influence energy in GridLAB-D compared to SAM can help bound any comparison of the results from the two programs.

\subsection{Results}

A variety of different scenarios were explored to help test the implemented algorithm. Arrays with varying degrees of tilt and orientation aspects were simulated for one year in both software packages. Shading factors were applied to different scenarios to ensure the modeling of decreased solar output and cloud transients could be represented. In each of these cases, the incident plane insolation for the PV array and the final DC power output of the array were compared.

All results are run on a common area using the properties outlined in Table 1. The properties represent physical characteristics and ratings of the photovoltaic array simulated. The rating is the overall expected output value of the PV array, which is closely tied to the area and efficiency. The area defines the surface 
area that will absorb sunlight to generate electricity, and the efficiency defines how much of the incident solar radiation is converted to electricity. As a simple relationship, the rating is typically related to an ideal insolation of $1000 \mathrm{~kW} / \mathrm{m}^{2}$ and the equation:

$$
\text { Rating }=1000 \frac{\mathrm{kW}}{\mathrm{m}^{2}} * \text { area } * \text { efficiency. }
$$

The soiling and derating factors are used to further represent reductions in efficiency in the array. The soiling factor represents dirt and other obscurations on the array, preventing the full insolation from reaching the silicon. The derating factor is meant to account for inefficiencies introduced during the manufacturing process. These properties represent the basis needed by GridLAB-D to define the common solar array. The tilt angle, azimuth, and shading factor were varied for different aspects of the validation tests. Weather information was read in from the Typical Meteorological Year (TMY) data for Yakima, Washington [7].

Table 1. Common Properties for PV Model Testing

\begin{tabular}{|c|c|}
\hline Property & Value \\
\hline Rating & $4.0 \mathrm{kVA}$ \\
\hline Area & $29.6296 \mathrm{~m}^{2}$ \\
\hline Efficiency & 0.135 \\
\hline Soiling & 0.95 \\
\hline Derating & 0.95 \\
\hline
\end{tabular}

\subsubsection{Tilted Array - 45 degree Tilt}

The first scenario examined was for a fixed-axis array tilted at 45-degrees and facing towards the equator. No shading factors were applied, so the test is merely to verify the overall insolation model and power output for the new GridLAB-D solar model.

\subsubsection{Insolation}

The first item to compare is how the incident solar radiation on the array compares to the values obtained from NREL's SAM program. Since both programs are utilizing the same base algorithm, results should be nearly identical. Figure 3 shows a week in July for both programs. The plot in Figure 3 only appears to have the GridLAB-D information, merely because it overlaps the SAM data and the plot can't render any minor differences. The SAM data does show some minor differences, especially around the sunset of July $13^{\text {th }}$. 


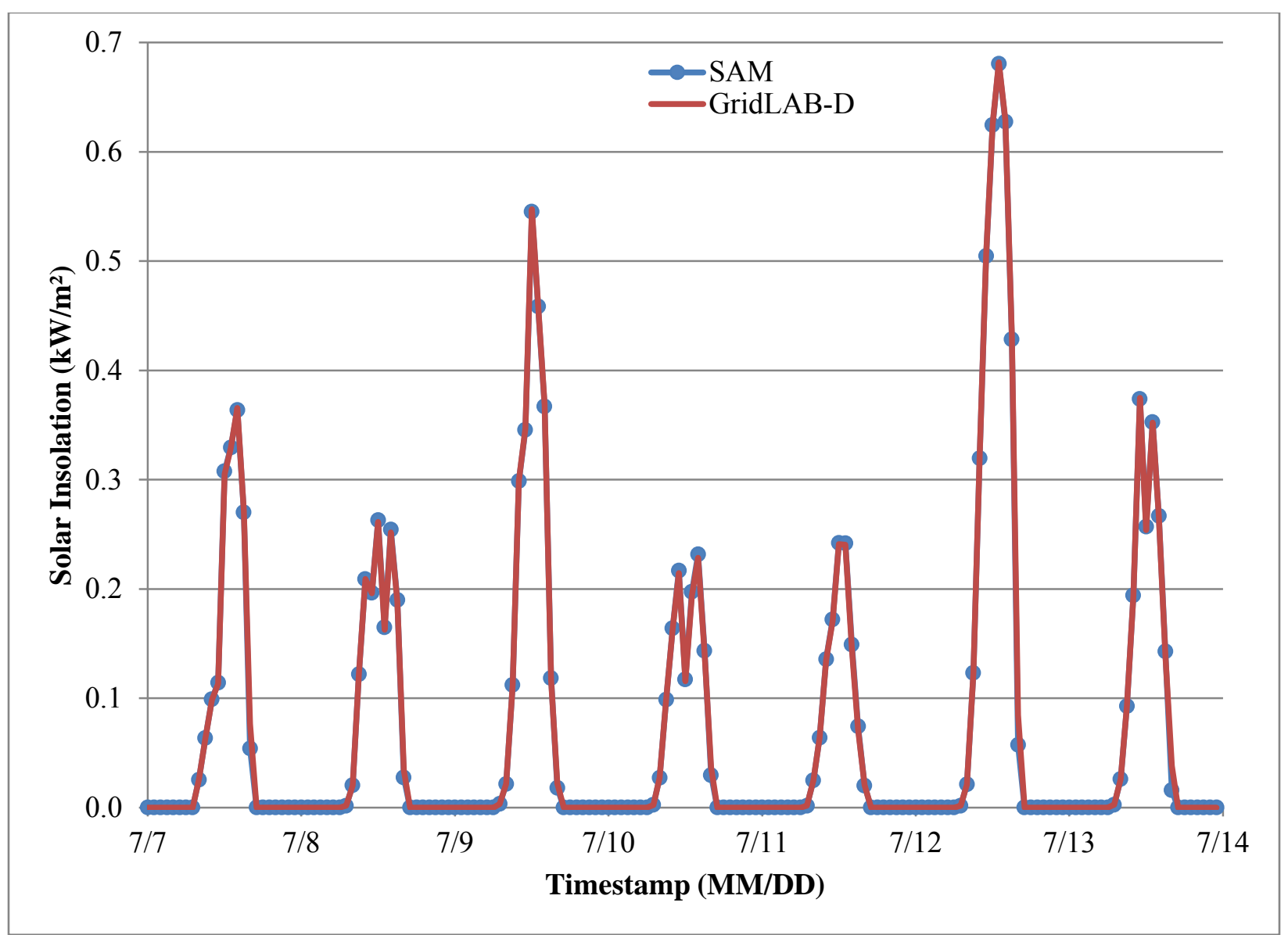

Figure 3. Solar insolation subset comparison $-45^{\circ}$ tilt

To help examine any differences obscured by the plot, the absolute value of the difference between both programs was taken and accumulated for a full year. Figure 4 shows the results of that comparison. Unlike the results of Figure 3, there are some differences in the solar insolation. However, it is useful to point out the scaling on the $y$-axis of the plot. The maximum values are only peaking above 40 Watts per square meter twice in the year. For the majority of the year, the difference is less than 10 Watts per square meter. 


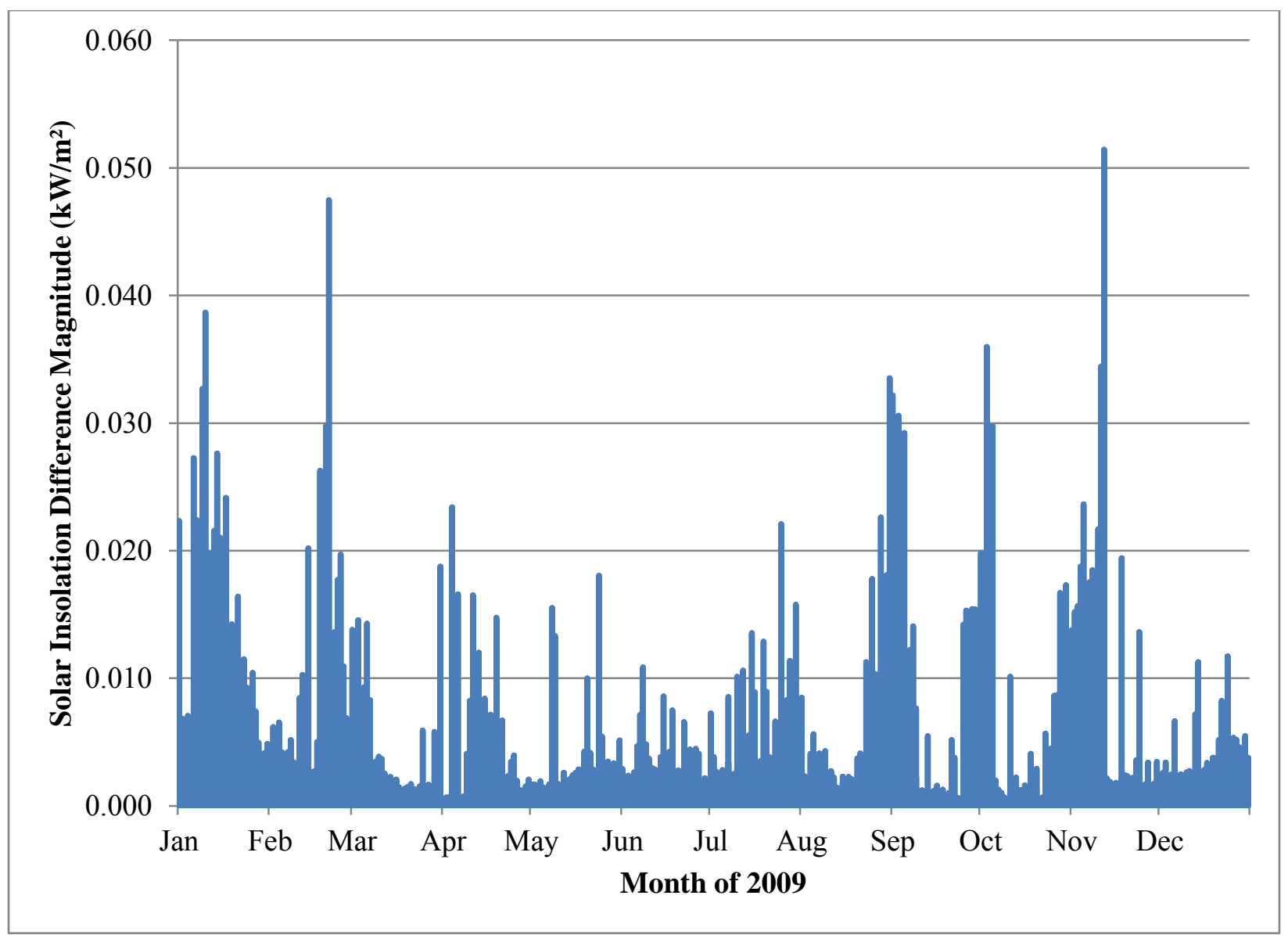

Figure 4. Insolation differences between GridLAB-D and SAM for entire year $-45^{\circ}$ tilt

\subsubsection{Power Output}

Complimentary to incident solar radiation, the power output from the photovoltaic array was also examined. Figure 5 shows the power output for the PV array during the exact same interval as Figure 3. Once again, the plot appears to only show one line for most of the simulation interval. This is a good indication the power models are aligning well, given the results of the insolation comparison in the previous subsection. As with the insolation test, the subtle difference is clearest at the end of daylight on July 13. 


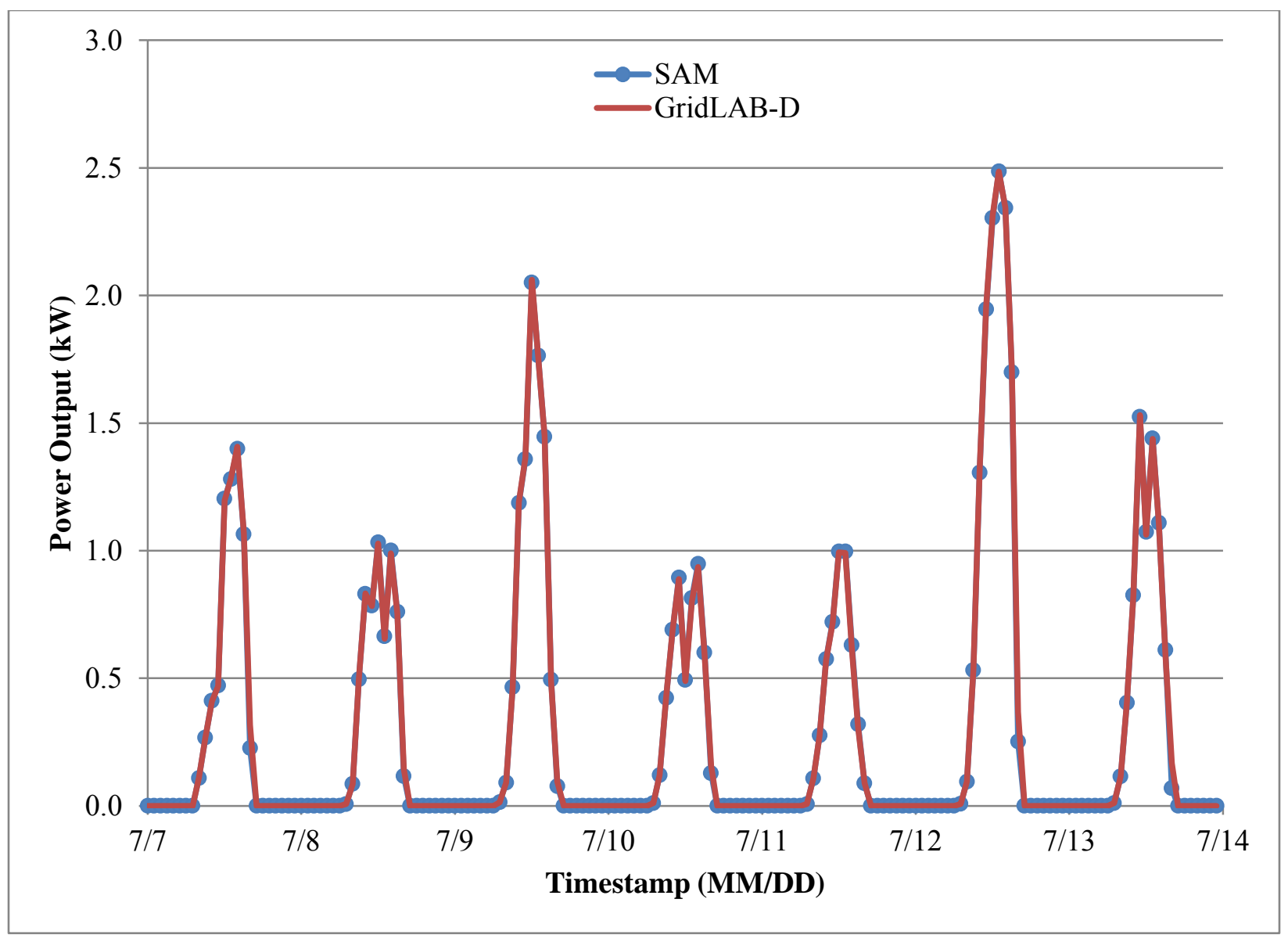

Figure 5. $\mathrm{PV}$ array power output comparison for data subset $-45^{\circ}$ tilt

As with the insolation results, any differences are lost to the plot rendering requirements. To examine the differences, the difference magnitude is plotted in Figure 6. As one would expect, the power output difference has the same shape as the solar insolation difference. A peak difference of a little over 0.20 $\mathrm{kW}$ was observed for the full year of data comparison. Considering the ideal array output is roughly 4.0 $\mathrm{kVA}$, this peak value represents approximately 5.3\% difference. Explanations for this difference will be included in the last section of this chapter. Accumulated over the entire year, the difference results in approximately $29.7 \mathrm{kWh}$ of difference out of a total energy output of almost $5100 \mathrm{~kW}(0.58 \%)$. 


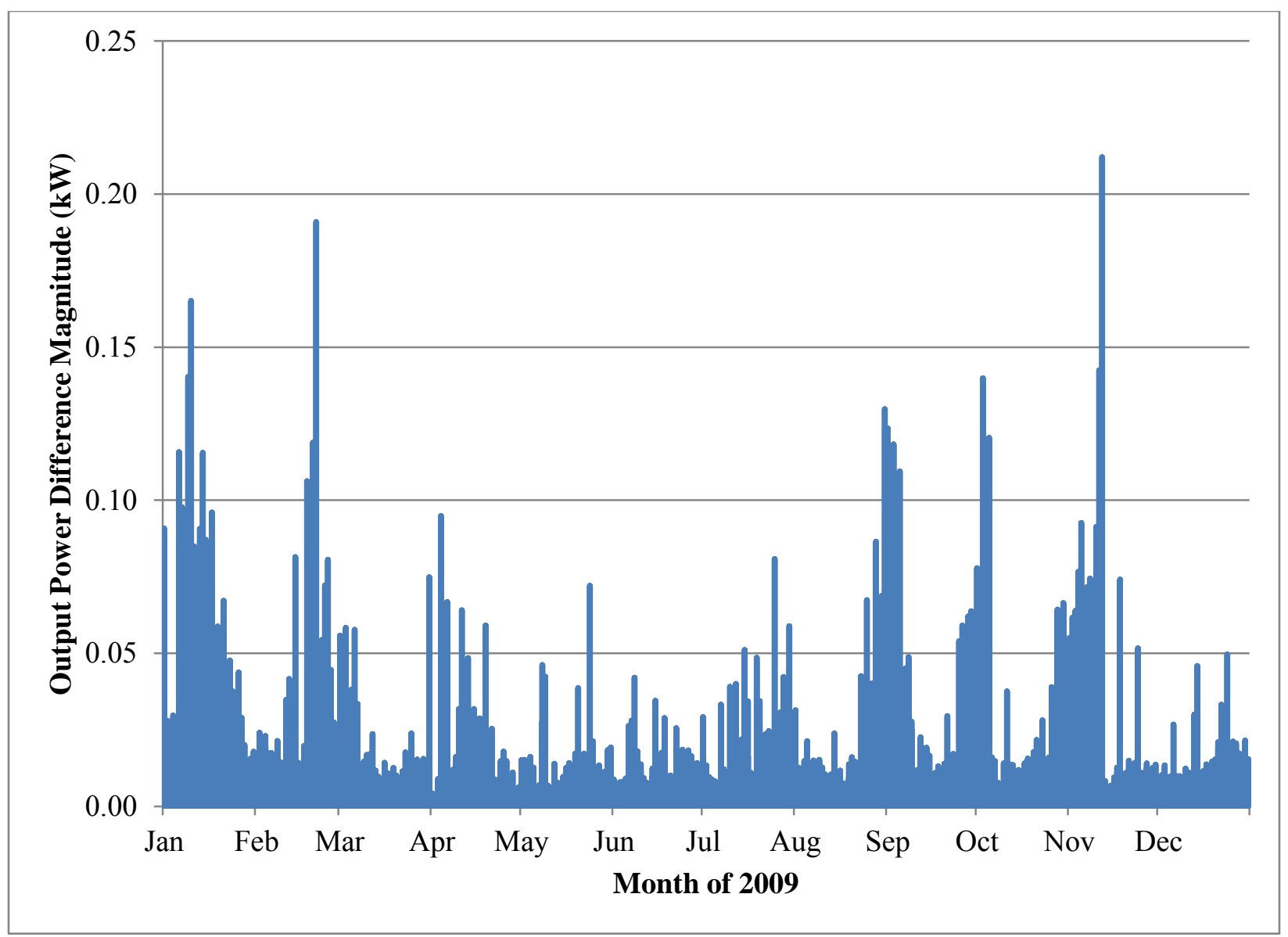

Figure 6. Power output differences between GridLAB-D and SAM for entire year $-45^{\circ}$ tilt

\subsubsection{Tilted Array with Shading -45 degree Tilt}

To further test the insolation and power models, the $45^{\circ}$ tilt array was subjected to an additional influence: shading factor. Shading factor is meant to simulate clouds passing overhead or other reductions in solar output. Figure 7 shows the shading factor utilized during every day of the year-long simulation. It is useful to note that the shading factor follows the convention of NREL's SAM software, with 1.0 being no shading and 0.0 being full shading. 


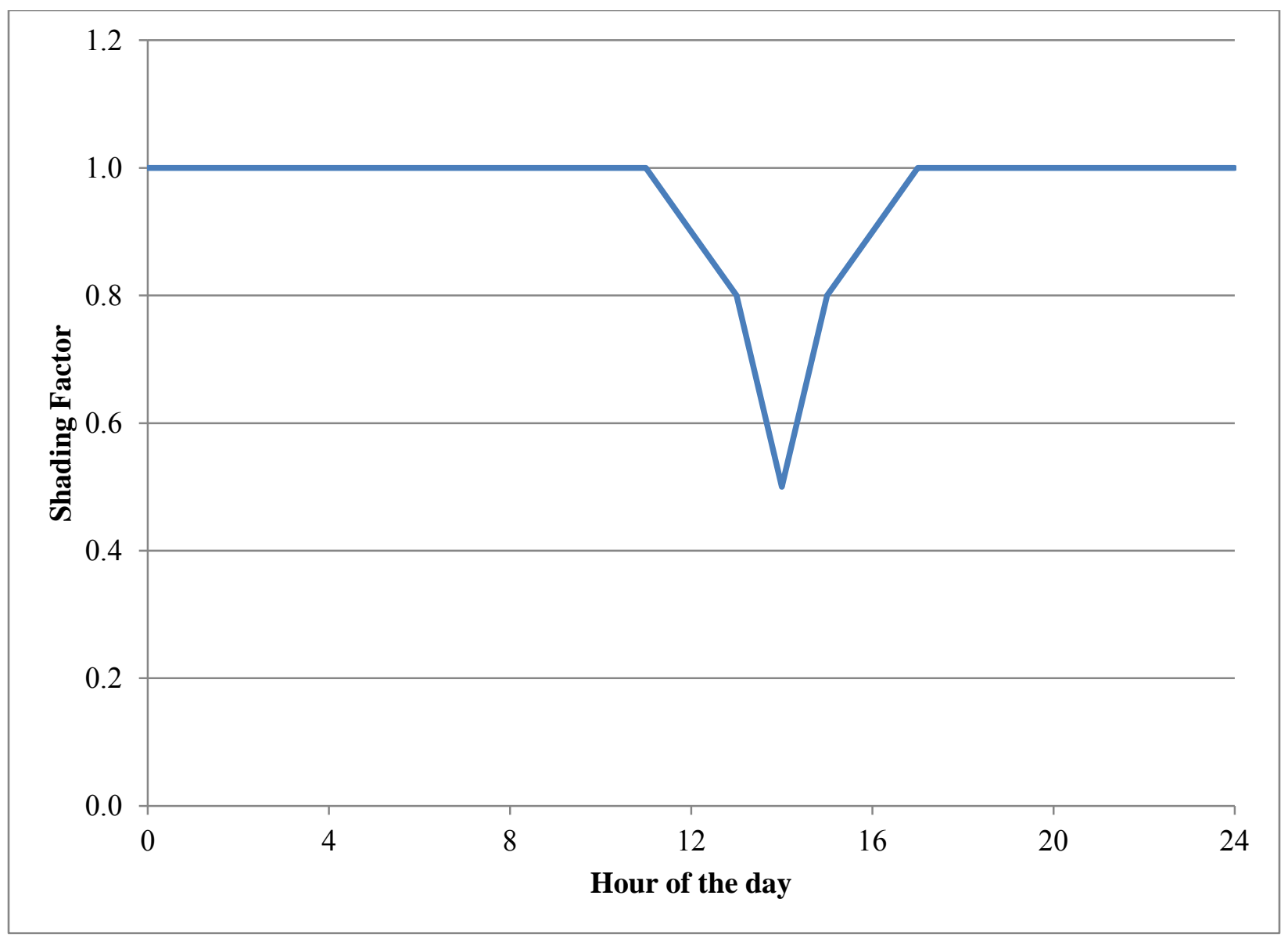

Figure 7. Shading factors applied to daily solar insolation

\subsubsection{Insolation}

Figure 8 below shows the insolation comparison for GridLAB-D and SAM for the same week in July as the previous example, but with shading factors applied. As with the previous plot, only the GridLAB-D output appears present, due to limitations on the plotting display. It is interesting to note the sharp transitions in the afternoon of July 10. This is a direct result of the shading factor application. 


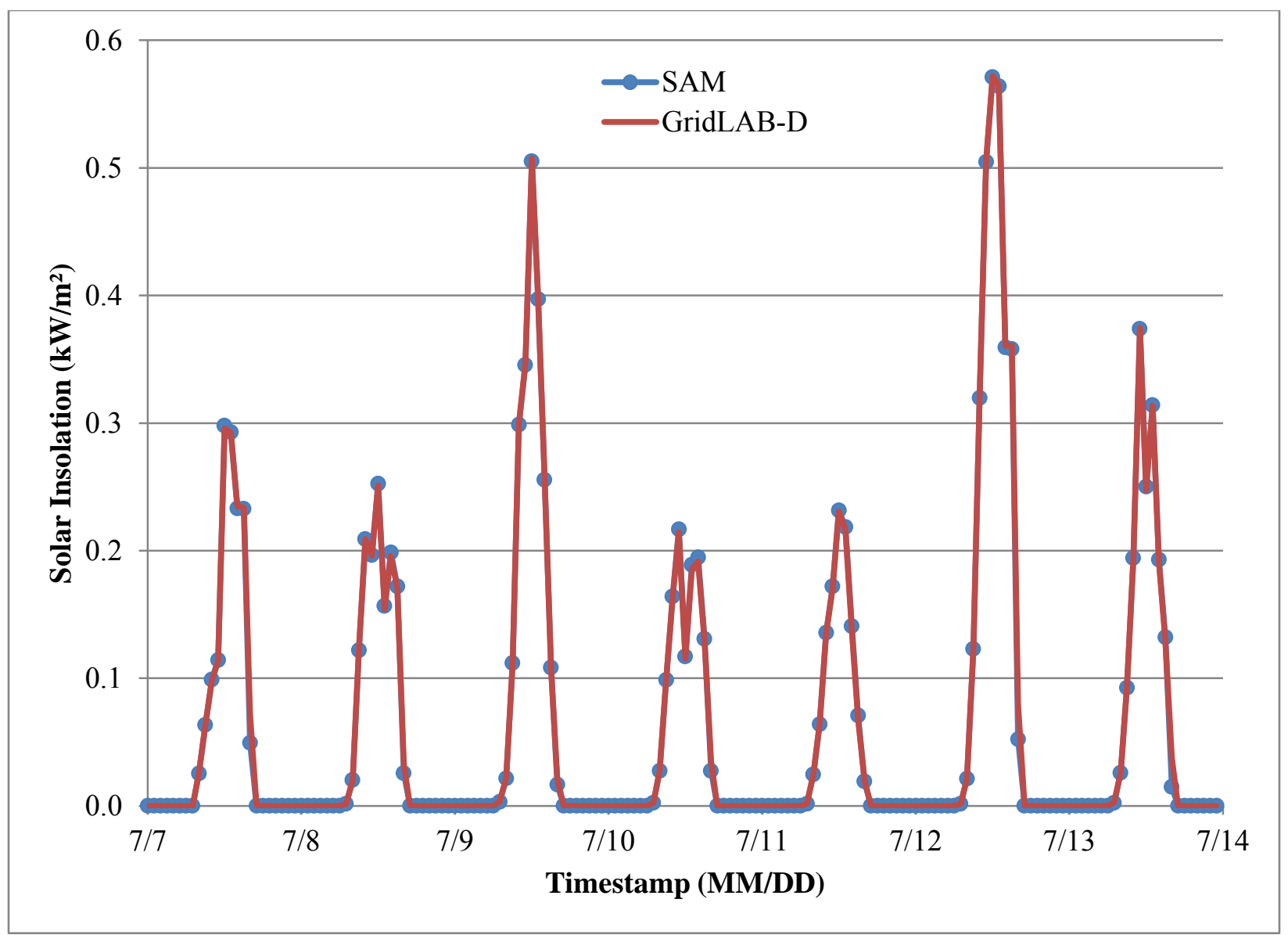

Figure 8. Solar insolation subset comparison $-45^{\circ}$ tilt with shading factors

As with the previous section, it is useful to examine the difference in insolation directly. Figure 9 shows the magnitude of the difference for all months of the year. The values look nearly identical to Figure 4 in the previous section. Including the shading factor had a minimal impact on the difference, indicating the shading factor is handled in a nearly-identical fashion between the GridLAB-D and SAM implementations. This is also an indication that the greatest difference between the two implementations appears in the diffuse radiation. This will be explored at the end of this chapter. 


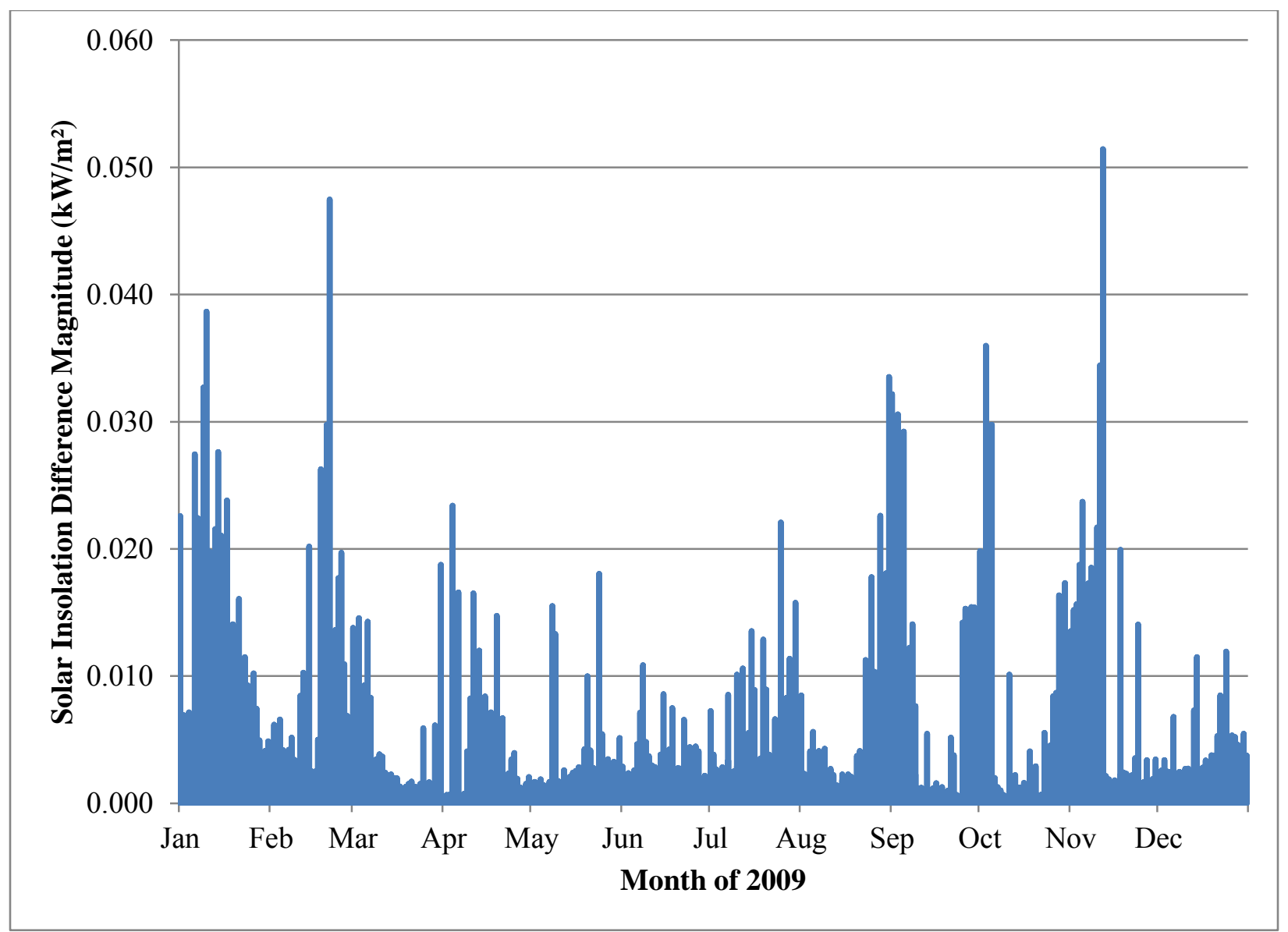

Figure 9. Insolation differences between GridLAB-D and SAM for entire year $-45^{\circ}$ tilt with shading factors

\subsubsection{Power Output}

As with the insolation output, it is also useful to plot the direct power output of the photovoltaic array. Figure 10 shows the comparison of the GridLAB-D and SAM output for the common July week. As one would expect from the prior results, Figure 10 appears to only show the GridLAB-D output. Per the previous results, this is an indication of a good match between the two implementations, as well as limitations in the plotting software. 


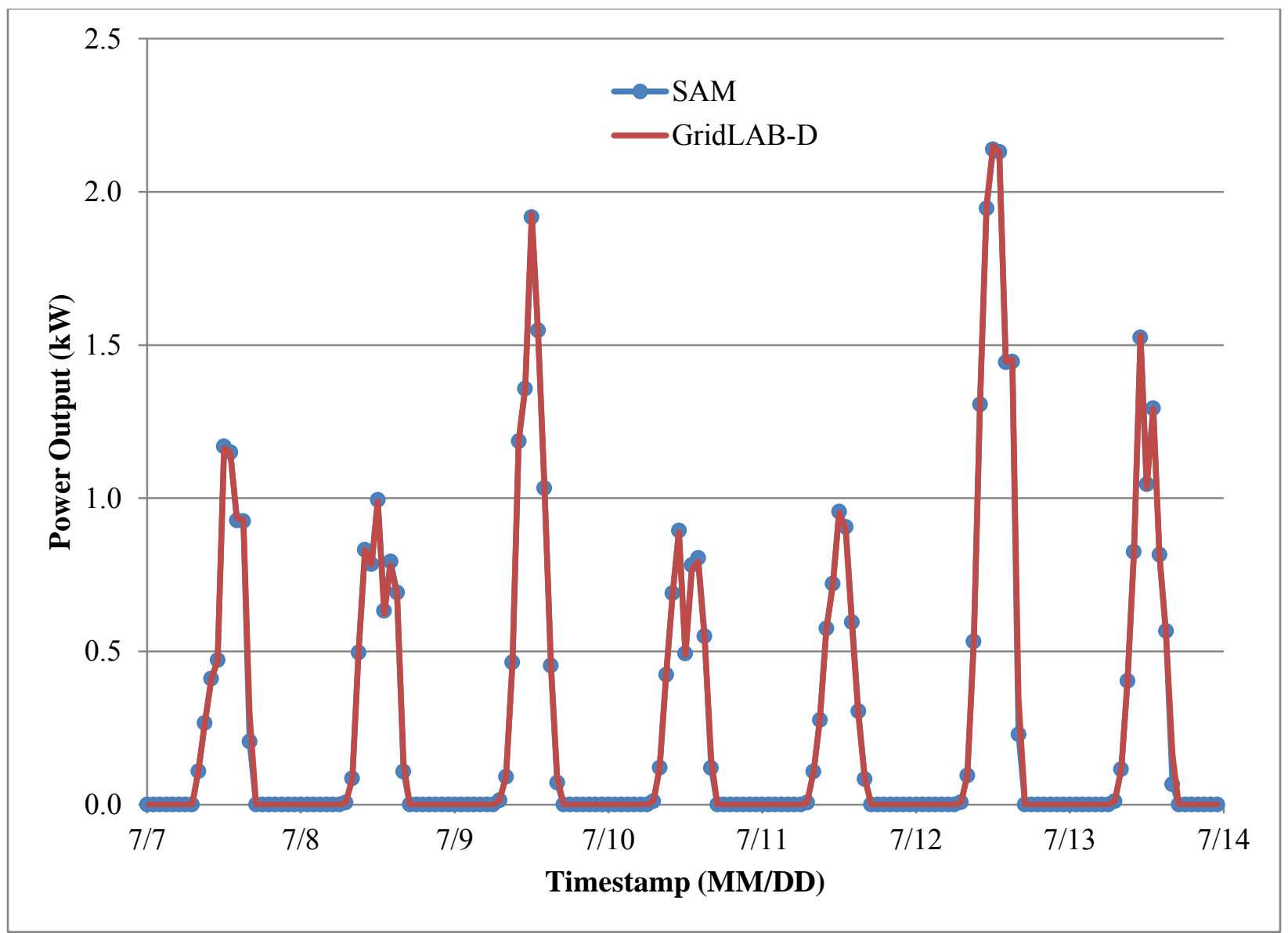

Figure 10. $\mathrm{PV}$ array power output comparison for data subset $-45^{\circ}$ tilt with shading factors

To examine the differences between the outputs in greater detail, the magnitude of the difference between SAM and GridLAB-D was again plotted. Figure 11 shows the difference. As with the insolation result, the output looks nearly identical to the previous, shading-free case. Furthermore, if the insolation matches that of SAM, as in the previous case, the power output is expected to match as well. 


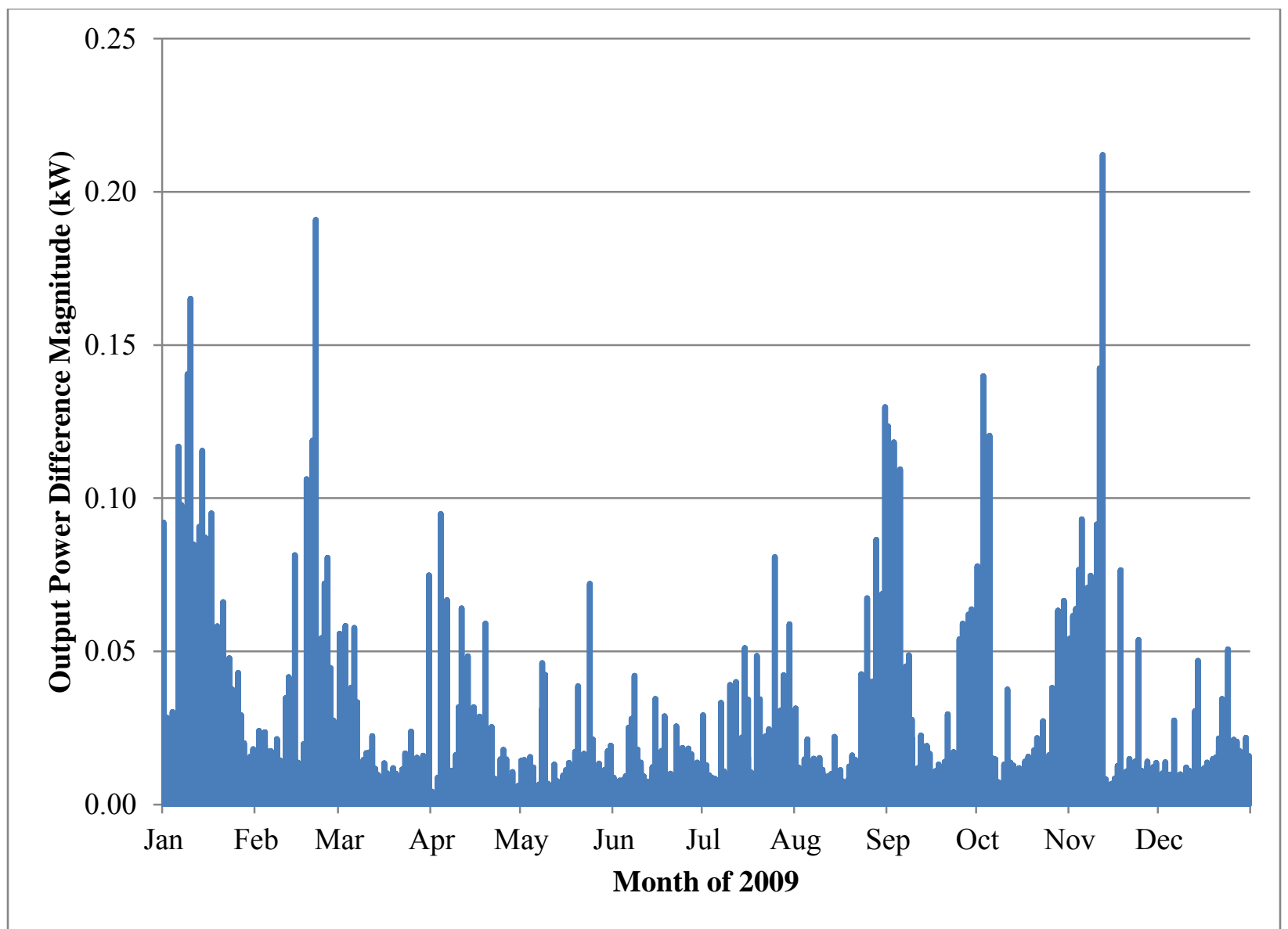

Figure 11. Power output differences between GridLAB-D and SAM for entire year $-45^{\circ}$ tilt with shading factors

\subsubsection{Tilted Array - 90 degree tilt}

A third test set was selected to put more emphasis on the diffuse radiation contributions to the system. The array was oriented such that a tilt of 90 degrees was utilized. This tilting represents a verticallyoriented PV panel. Despite still facing the equator, this orientation does not adequately capture the directnormal component of the solar insolation very well. Therefore, certain portions of the day will have a much greater diffuse-horizontal radiation influence.

\subsubsection{Insolation}

In line with the previous sections, a common week from the data set is plotted from both GridLAB-D and SAM. Figure 12 shows the result, which is again dominated by the GridLAB-D output. Even in this lessthan-optimal orientation, the underlying model between SAM and GridLAB-D appears to produce identical results. 


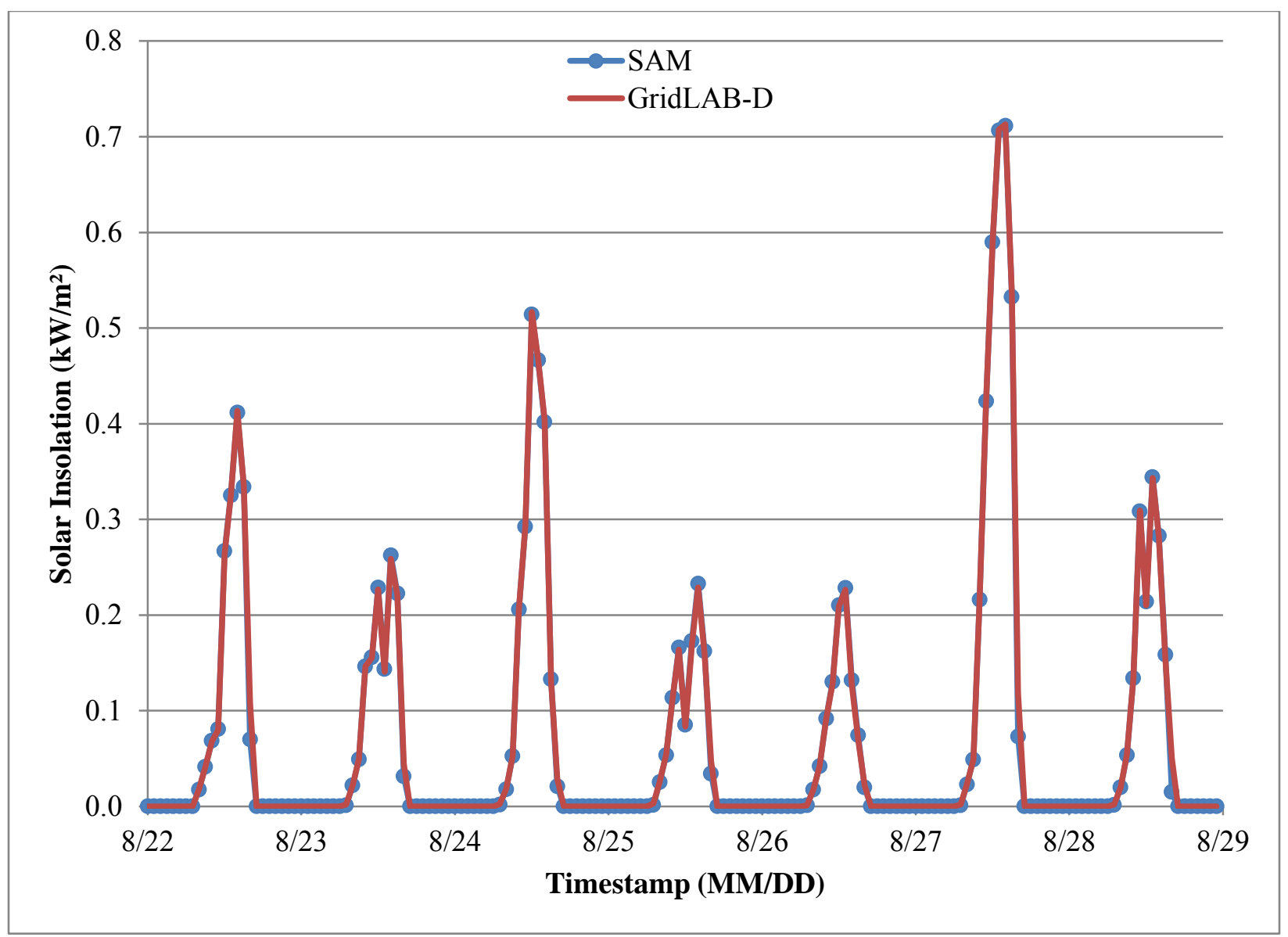

Figure 12. Solar insolation subset comparison $-90^{\circ}$ tilt

To overcome the limitations of the output plot, the magnitude of the annual difference is plotted again. In Figure 13, it is seen that the difference between SAM and GridLAB-D is very similar to what it was for the $45^{\circ}$ cases. This representation provides a couple insights. First off, it indicates that the SAM and GridLAB-D implementations are still behaving in a nearly identical fashion, even at this extreme tilt angle. It also indicates there may be some extra functionality or fundamental modeling differences between SAM and GridLAB-D for the days of particularly high differences. There may be additional environmental variables handled by SAM to influence the insolation values, or there may be a subtle implementation difference between the two software pieces. 


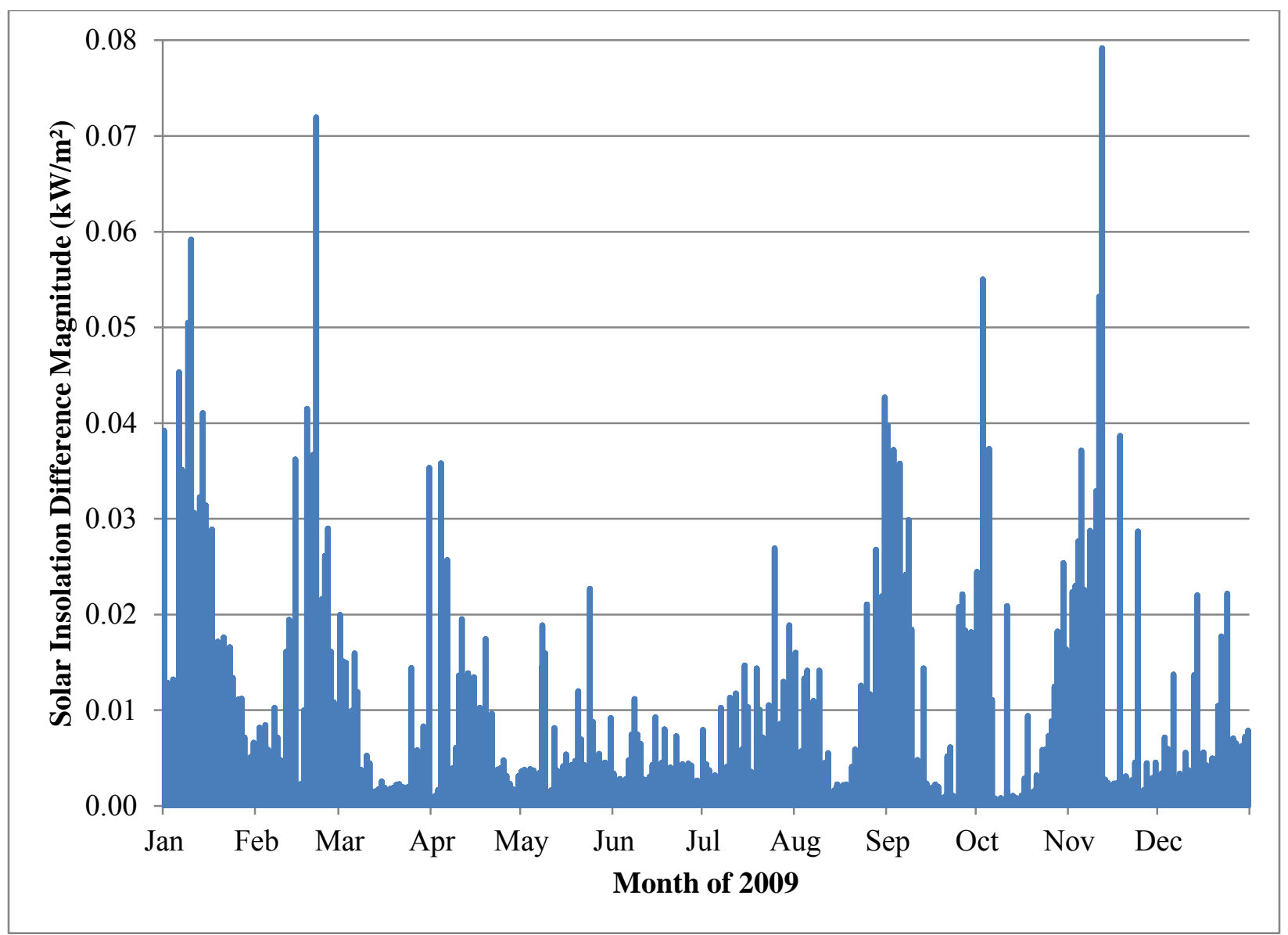

Figure 13. Insolation differences between GridLAB-D and SAM for entire year $-90^{\circ}$ tilt

\subsubsection{Power Output}

As with the previous examples, it is also useful to compare the PV array power output for both GridLAB$\mathrm{D}$ and SAM. Figure 14 shows the power output for the two under the $90^{\circ}$ tilt case. Once again, the results appear identical, aside from a minor difference near the end of August 28. This coarse view of a sample week continues to reinforce that both GridLAB-D and SAM are calculating photovoltaic output in a similar fashion. 


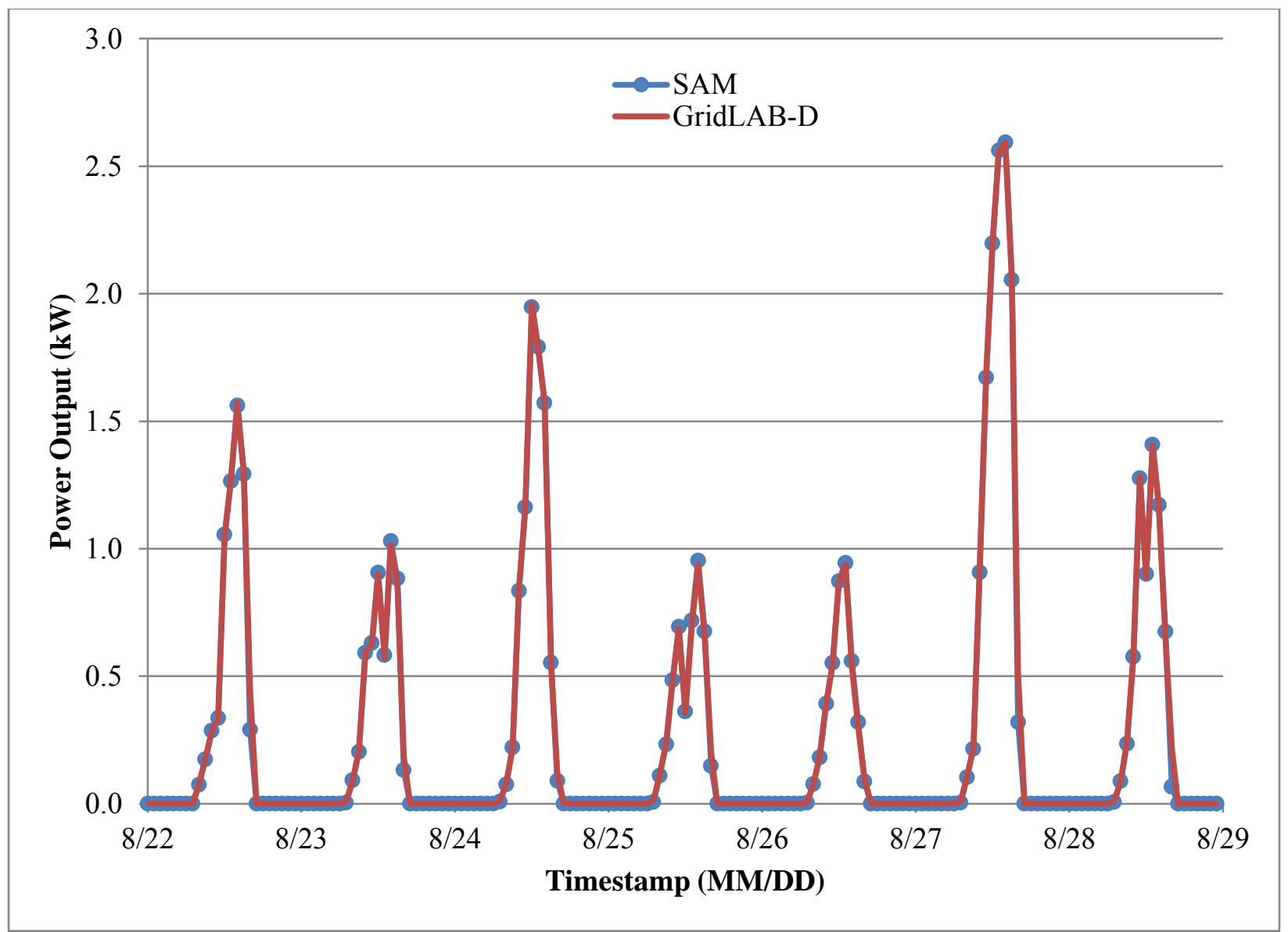

Figure 14. $\mathrm{PV}$ array power output comparison for data subset $-90^{\circ}$ tilt

Once again, it is useful to directly examine the magnitude of the difference between the SAM and GridLAB-D implementations. Figure 15 shows the difference between the power output of SAM and GridLAB-D for the entire year of simulations. The difference between the two implementations is still very small, but is slightly higher than that of the $45^{\circ}$ tilt. The largest difference from the $45^{\circ}$ model is about 60Watts for one period in December. Despite this slightly higher difference, the overall trend of the output difference is the same. As mentioned in the insolation result, this may be an indication that there are some small differences in the algorithm implementations. 


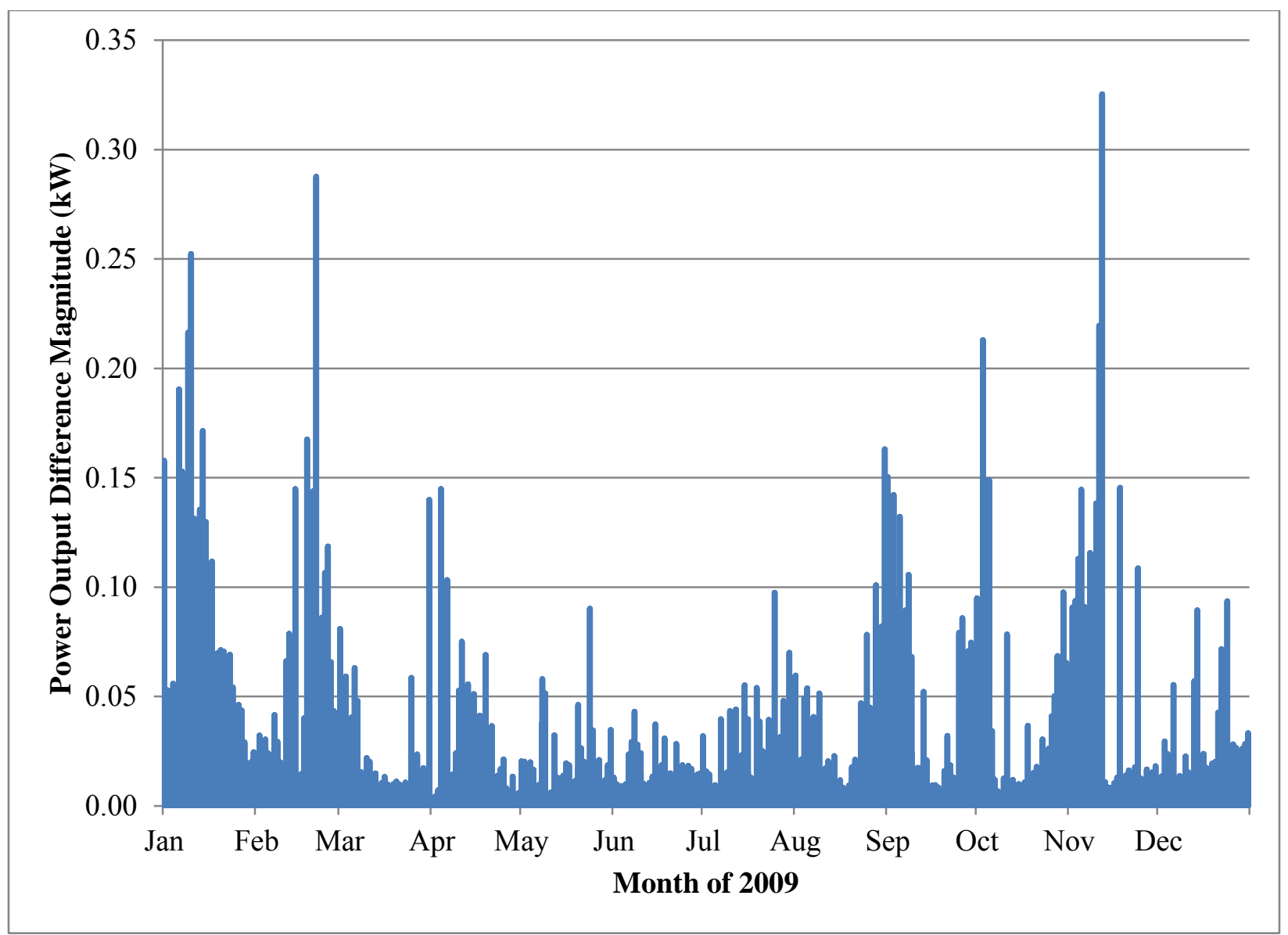

Figure 15. Power output differences between GridLAB-D and SAM for entire year $-90^{\circ}$ tilt

\subsubsection{Difference Summary}

The plots through this section have shown that GridLAB-D and SAM are providing nearly identical results for a particular implementation of photovoltaic arrays. However, differences have still existed between the implementations. Table 2 quantifies the overall results from the difference figures in this section. Table 2 also includes the values from the original implementations demonstrated in Figure 1 and Figure 2. It is important to note that the insolation and energy categories are accumulations for the full year of simulation. The power values are the maximum difference compared against the overall inverter rating ( $4 \mathrm{kVA})$. As the table shows, power output differences show the largest value. With solar insolation and energy output, the largest difference of the final three models is $0.8 \%$ of the total annual PV output. It was also for the $90^{\circ}$ tilt case, which has a lower likelihood of deployment compared to intermediate tilt levels. 
Table 2. Magnitude of Difference for Different Scenarios

\begin{tabular}{|c|c|c|c|}
\hline Scenario & Output & Numeric Difference & $\begin{array}{c}\text { Absolute } \\
\text { Difference (\%) }\end{array}$ \\
\hline \multirow{3}{*}{$\begin{array}{c}45^{\circ} \text { tilt }- \text { Original } \\
\text { Models }\end{array}$} & Insolation & $165.66 \mathrm{kWh} / \mathrm{m}^{2}$ & 10.89 \\
\hline & Energy & $641.13 \mathrm{kWh}$ & 12.58 \\
\hline & Power & $1.08 \mathrm{~kW}$ & 27.12 \\
\hline \multirow{3}{*}{$\begin{array}{c}45^{\circ} \text { tilt }- \text { New Solar, } \\
\text { Old Efficiency }\end{array}$} & Insolation & $5.95 \mathrm{kWh} / \mathrm{m}^{2}$ & 0.39 \\
\hline & Energy & $743.08 \mathrm{kWh}$ & 14.58 \\
\hline & Power & $1.22 \mathrm{~kW}$ & 30.47 \\
\hline \multirow{3}{*}{$45^{\circ}$ tilt } & Insolation & $5.95 \mathrm{kWh} / \mathrm{m}^{2}$ & 0.39 \\
\hline & Energy & $29.67 \mathrm{kWh}$ & 0.58 \\
\hline & Power & $0.21 \mathrm{~kW}$ & 5.30 \\
\hline \multirow{3}{*}{$45^{\circ}$ tilt with shading } & Insolation & $5.93 \mathrm{kWh} / \mathrm{m}^{2}$ & 0.43 \\
\hline & Energy & $29.16 \mathrm{kWh}$ & 0.62 \\
\hline & Power & $0.21 \mathrm{~kW}$ & 5.30 \\
\hline \multirow{3}{*}{$90^{\circ}$ tilt } & Insolation & $7.87 \mathrm{kWh} / \mathrm{m}^{2}$ & 0.69 \\
\hline & Energy & $32.05 \mathrm{kWh}$ & 0.80 \\
\hline & Power & $0.33 \mathrm{~kW}$ & 8.13 \\
\hline
\end{tabular}

For the final model implementation, the differences shown in Table 2 are predominately associated with one particular source of the solar irradiation. The shading factor results earlier showed little difference from the non-shading factor simulations. This indicates the direct-normal radiation is not causing a significant issue and the diffuse radiation contributions are likely causing the issue. For the $45^{\circ}$ tilt case examined earlier, Figure 16 and Figure 17 show the differences in the GridLAB-D direct normal and diffuse horizontal radiation compared to the SAM versions. For the entire year, the direct-normal irradiance only has a peak difference of about $7.4 \mathrm{~W} / \mathrm{m}^{2}$, with an accumulated error of $0.97 \mathrm{kWh} / \mathrm{m}^{2}$. However, the diffuse-horizontal irradiance has significantly higher differences with a peak around 51.4 $\mathrm{W} / \mathrm{m}^{2}$ and an accumulated difference of $5.67 \mathrm{kWh} / \mathrm{m}^{2}$. 


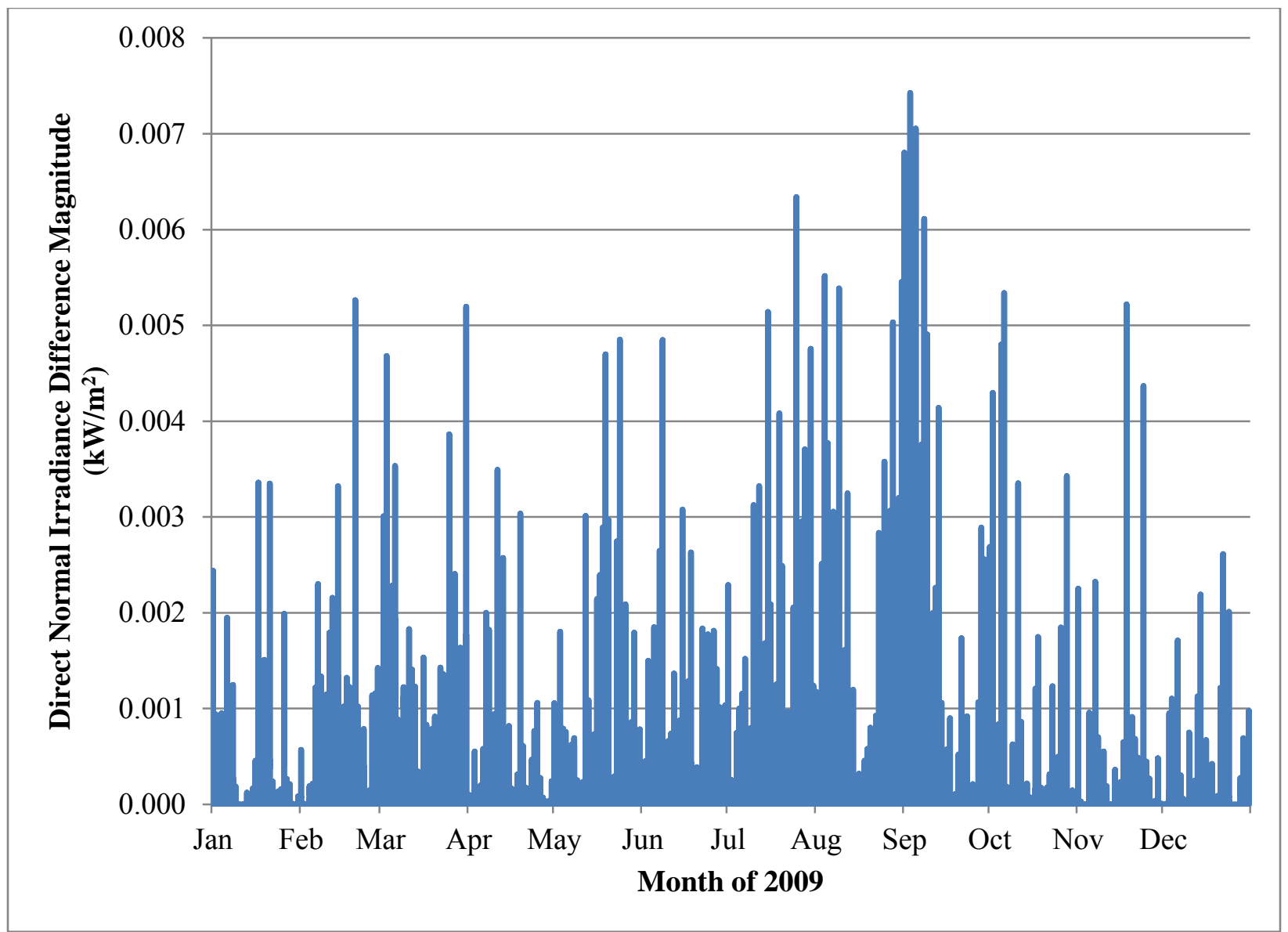

Figure 16. Differences for direct-normal irradiance between GridLAB-D and SAM for entire year $-45^{\circ}$ tilt 


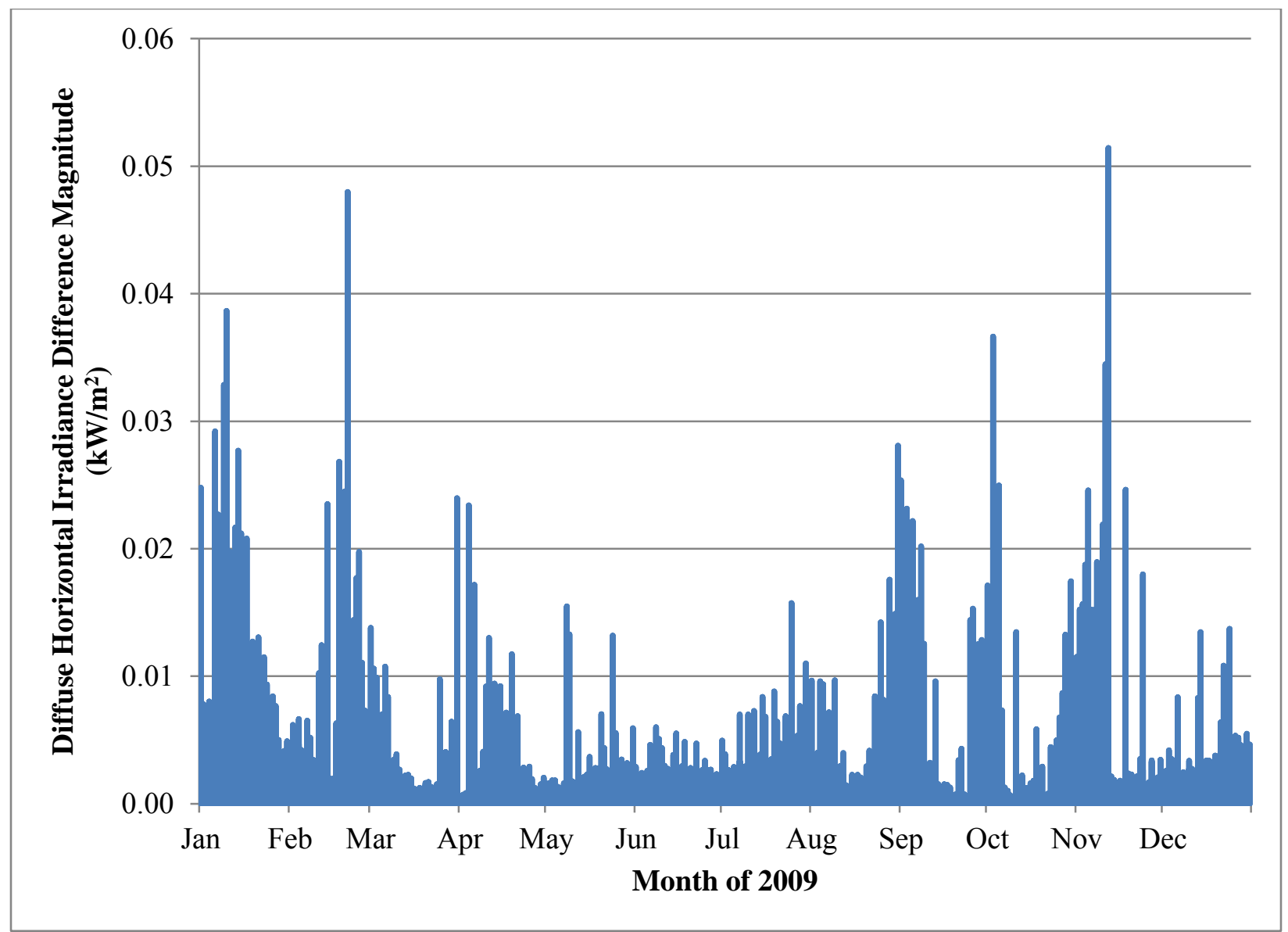

Figure 17. Differences for diffuse-horizontal irradiance between GridLAB-D and SAM for entire year $45^{\circ}$ tilt

The overall shape of the diffuse-horizontal differences in Figure 17, compared with Figure 4, shows a high correlation between the overall difference and the diffuse radiation model. Furthermore, the accumulated difference value of $5.67 \mathrm{kWh} / \mathrm{m}^{2}$ is $95.3 \%$ of the overall difference of $5.95 \mathrm{kWh} / \mathrm{m}^{2}$ in the solar irradiance. It is useful to note that the $95.3 \%$ is probably higher than the actual difference contribution, since the addition of the direct-normal difference and diffuse-horizontal difference are not the same as the total insolation difference $\left(6.64 \mathrm{kWh} / \mathrm{m}^{2}\right.$ compared to the observed value of 5.95 $\mathrm{kWh} / \mathrm{m}^{2}$ ). This is due to the values being separated for this analysis, while in the actual simulation they are combined. An under-error in direct-normal and over-error in diffuse-horizontal could cancel out to be closer to the correct value.

Examining the more prominent peaks of Figure 17 shows an interesting trend in the data. The large difference times are predominately associated with times between 16:00 and 18:00. This indicates most of the differences are being accumulated during the last hours of daylight in the day and may be an indication sunset is being handled slightly different in SAM than it is in GridLAB-D. A subsequent plot, Figure 18, shows the direct difference of the diffuse-horizontal data. Overall, the difference is much more balanced. Furthermore, the prominent "evening" peaks in Figure 18 are predominately negative, indicating an underestimate of the diffuse-horizontal radiation. 


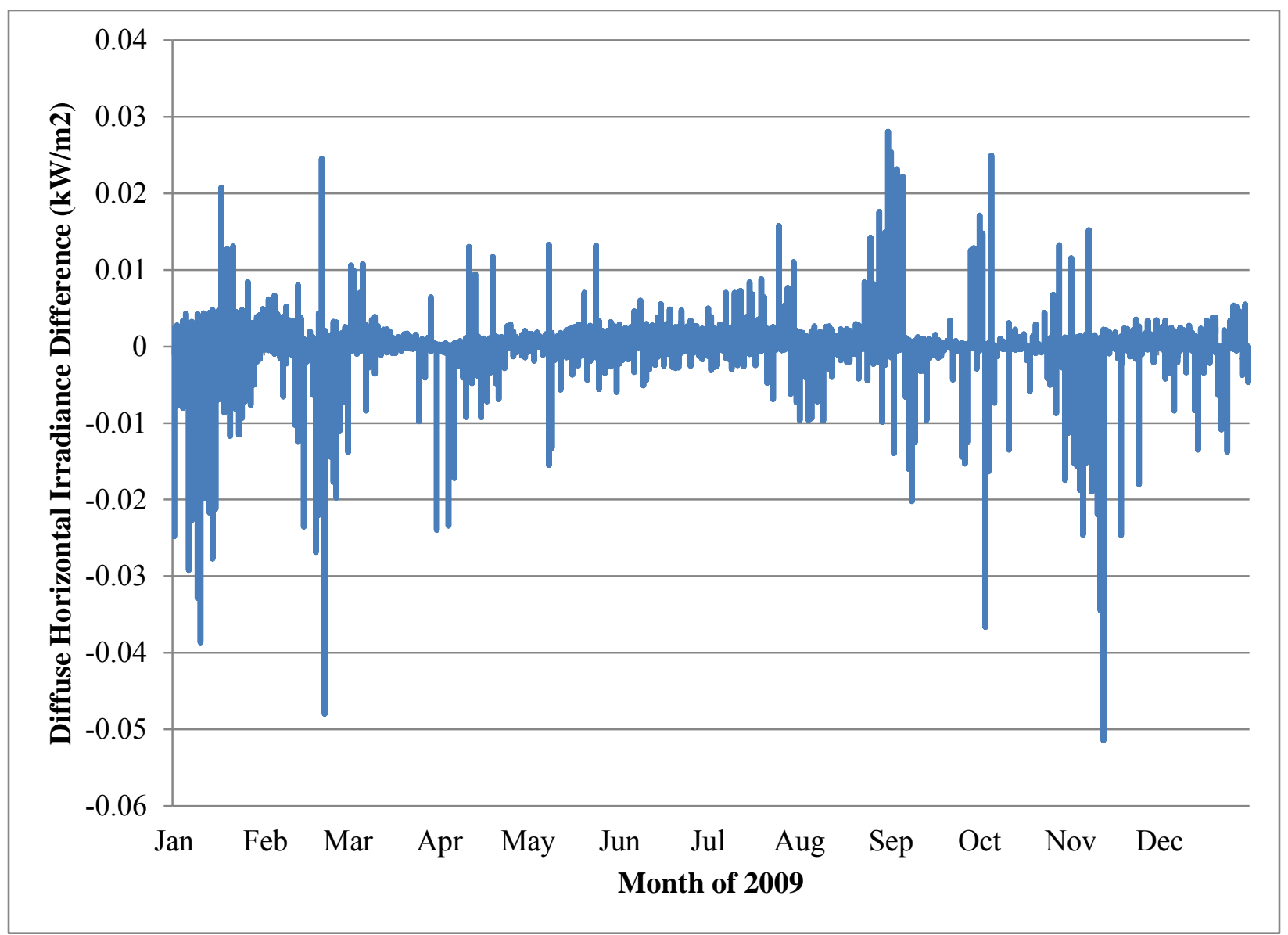

Figure 18. Signed differences for diffuse-horizontal irradiance between GridLAB-D and SAM for entire year $-45^{\circ}$ tilt

The information in Table 2 and Figure 16 to Figure 18 show there are clearly some differences between the SAM and GridLAB-D implementations. Over the course of an entire year, the energy difference is fairly minor. For the typical, system-level study that GridLAB-D is conducting, this margin of error is sufficiently small. In such studies, uncertainty in the direct feeder data and specific end-use load parameters are typically in this range. Furthermore, the aggregation of a large population of end-use devices and PV arrays will lose the uncertainty into the overall behavior of the system. 


\subsection{Final Thoughts}

The implementation of the Solar Position 2, Perez tilt model, and flat plate simple efficiency model in GridLAB-D resulted in a much more accurate representation of photovoltaic systems for study. The differences between the GridLAB-D and SAM implementations were very small, with the largest accumulated difference for a year-long simulation being less than $1.0 \%$. Later study showed these differences are predominately associated with the diffuse-horizontal component of the solar irradiance, and are dispersed in a uniform manner as over-estimates and under-estimates, when compared to the SAM results. There are clearly some small differences in the model implementation between the two software projects. However, the differences are relatively small (under $1.0 \%$ for the yearly accumulation), and the overall results are very closely aligned, especially when comparing the legacy GridLAB-D model and SAM model results.

With the accumulated difference very small, this new capability allows GridLAB-D to better model distributed photovoltaic generation. Building off of the detailed model incorporated into the NREL SAM software, the new GridLAB-D implementation will yield more accurate results for solar integration studies. With the common solar basis model, individual installations inside GridLAB-D could then be examined in further detail inside SAM. This loose connection allows both the system-level impacts of solar to be evaluated (GridLAB-D), as well as the capability to examine how an individual customer may be impacted by changes on the distribution grid (SAM). 


\subsection{References}

[1] United States Energy Information Administration, "Table 10.9 Photovoltaic Cell and Module Shipments by Sector and End Use, 1989-2010" in Annual Energy Review 2011, September 27, 2012, pp. 299. [Online]. Available: http:/www.eia.gov/totalenergy/data/annual/pdf/sec10_23.pdf.

[2] National Renewable Energy Laboratory, "Solar Advisor Model," [Online]. Available: http://sam.nrel.gov. Accessed May 20, 2012.

[3] Pacific Northwest National Laboratory, “GridLAB-D," [Online]. Available: http://www.gridlabd.org, March 2012. Accessed September 20, 2012.

[4] Duffie, J. and W. Beckman, Solar Engineering of Thermal Processes, John Wiley \& Sons, Inc., Hoboken, New Jersey, USA, 1975.

[5] National Renewable Energy Laboratory - Martin Rymes, "Solar Position and Intensity 2.0," [Online]. Available: http://rredc.nrel.gov/solar/codesandalgorithms/solpos/, February 2000. Accessed July 20, 2012.

[6] Perez, R., I. Pierre, R. Seals, J. Michalsky, and R. Stewart, "Modeling Daylight Availability and Irradiance Components from Direct and Global Irradiance," Solar Energy, vol. 44, no. 5, pp. 271 $289,1990$.

[7] National Renewable Energy Laboratory, "National Solar Radiation Data Base - 1961-1990: Typical Meteorological Year 2," [Online]. Available: http://rredc.nrel.gov/solar/old_data/nsrdb/1961-1990/tmy2/, Accessed May 20, 2012. 


\section{Distribution}

No. of

Copies

1 Dan Ton

Department of Energy, OE

1000 Independence Ave., SW

Routing OE-10

Washington, DC 20585

1 Ruchi Singh

American Transmission Company

PDF copy
No. of

Copies

4 Local Distribution

Pacific Northwest National Laboratory

Kevin Schneider

(PDF)

Janelle Hammerstrom

(PDF)

Francis Tuffner

(PDF)

Robert Pratt

(PDF)

Distr. 1 


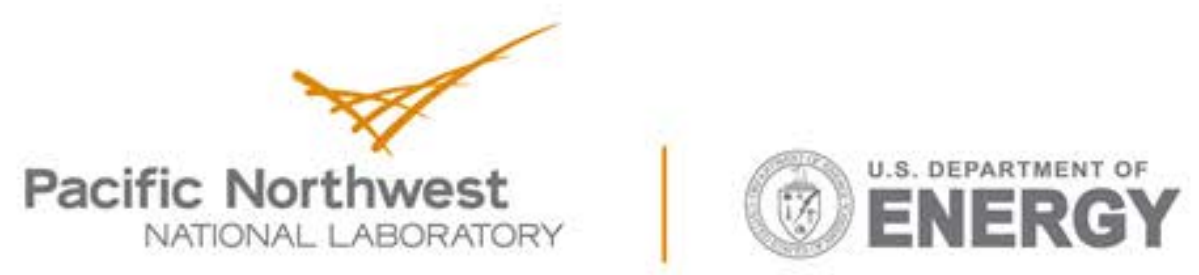

Proudly Operated by Battelle Since 1965

902 Battelle Boulevard

P.O. Box 999

Richland, WA 99352

1-888-375-PNNL (7665)

www.pnnl.gov 